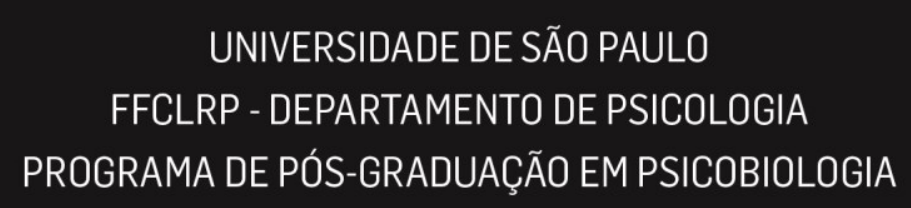

Estêvão Gonçalves Bittar

\title{
Da análise do comportamento à síntese comportamental: \\ Integrando modelos a partir de uma arquitetura computacional
}

Ribeirão Preto

2017 



\title{
Da análise do comportamento à síntese
}

\section{comportamental: Integrando modelos a partir de uma arquitetura computacional}

\author{
Versão original
}

Tese apresentada à Faculdade de Filosofia, Ciências e Letras de Ribeirão Preto da Universidade de São Paulo como requisito parcial para obtenção do título de Doutor em Ciências.

Área de Concentração: Psicobiologia Orientador: Prof. Dr. José Lino Oliveira Bueno

Ribeirão Preto 
Autorizo a reprodução e/ou divulgação total ou parcial da presente obra, por qualquer meio convencional ou eletrônico, para estudo e pesquisa, desde que citada a fonte.

\section{FICHA CATALOGRÁFICA}

Bittar, Estêvão Gonçalves

Da análise do comportamento à síntese comportamental: Integrando modelos a partir de uma arquitetura computacional / Estêvão Gonçalves Bittar; orientador José Lino Oliveira Bueno. Ribeirão Preto, 2017.

99 p.: il

Tese (Doutorado) - Departamento de Psicologia da Faculdade de Filosofia, Ciências e Letras de Ribeirão Preto da Universidade de São Paulo. Programa de Pós-Graduação em Psicobiologia. Área de concentração: Psicobiologia. 
Nome: Bittar, E. B.

Título: Da análise do comportamento à síntese comportamental: Integrando modelos a partir de uma arquitetura computacional.

Tese apresentada à Faculdade de Filosofia, Ciências e Letras de Ribeirão Preto da Universidade de São Paulo como requisito parcial para obtenção do título de Doutor em Ciências.

Aprovado em:

\section{Banca Examinadora}

Prof. Dr.

Instituição: Assinatura:

Prof. Dr.

Instituição:

Assinatura:

Prof. Dr.

Instituição: Assinatura:

Prof. Dr.

Instituição: Assinatura:

Prof. Dr.

Instituição: Assinatura: 

Para meus pais - apesar de que, a despeito do infinito amor que nos une, eles nunca lerão esta coisa.

Eu entendo. Completamente. 



\section{AGRADECIMENTOS}

Ao Dr. José Lino Oliveira Bueno, pela amizade e confiança. Sua forma de encorajar diferentes tipos de perguntas e pesquisas é um lembrete constante de que a busca científica deve ser ilimitada.

Ao Dr. Peter Killeen, uma das pessoas mais brilhantes (e, ao mesmo tempo, uma das mais carinhosas e receptivas) que já tive o prazer de conhecer.

Ao João Luís e todos os colegas do laboratório pela amizade e apoio.

Ao Dr. Antônio Carlos Roque da Silva Filho, por sua participação como assessor científico.

A toda a equipe do Programa de Pós-Graduação em Psicobiologia e do Departamento de Psicologia da Faculdade de Filosofia, Ciências e Letras de Ribeirão Preto.

Aos meus irmãos Netto, Lucas e Matheus. O simples prazer de tê-los ao meu lado dia após dia é o bastante para fazer a vida valer a pena.

À minha esposa Michelle, uma mulher tão linda, de tantas maneiras, que não consigo acreditar quão sortudo sou por ela ter dito "sim".

Ao meu avô, minhas avós e minha família estendida em todas as direções, por enriquecerem minha vida tanto.

Ao meu pai, João, e minha mãe, Tânia. O esforço que fiz para escrever esta tese empalidece diante do esforço que eu teria que fazer para descrever a profundidade do amor e admiração que sinto por eles. Por tê-los como meus pais, eu tenho tudo. 

A single system (mind) produces all aspects of behavior. It is one mind that minds them all. Even if the mind has parts, modules, components, or whatever, they all mesh together to produce behavior. [...] If a theory covers only one part or component, it flirts with trouble from the start (Newell, 1990, pp. 17-18). 



\section{RESUMO}

Bittar, E. G. (2017). Da análise do comportamento à síntese comportamental: integrando modelos a partir de uma arquitetura computacional. (Tese de Doutorado). Departamento de Psicologia, Faculdade de Filosofia, Ciências e Letras de Ribeirão Preto, Universidade de São Paulo, Ribeirão Preto.

Os modelos básicos da MPR são usados como blocos de construção de uma máquina estocástica que simula o responder operante. A máquina-MPR é então testada sob uma ampla variedade de condições experimentais, e prova sua capacidade de produzir com realismo: (a) distribuições de IRT, (b) padrões do responder intra-sessão, e (c) as relações entre taxa de reforçamento e taxa de resposta sob esquemas de intervalo e de razão. Em outro conjunto de experimentos, o modelo demonstra propriedades emergentes realistas e reproduz fenômenos bem conhecidos no âmbito dos esquemas múltiplos, como (d) contraste comportamental e (e) desaceleração da extinção - ambos além do alcance original da MPR.

No último capítulo do estudo, a máquina-MPR é dotada de um modelo de controle temporal. Essa nova configuração, chamada $t \mathrm{MPR}$, se mostra capaz de simular (f) o comportamento de timing que emerge sob esquemas previsíveis de intervalo, assim como (g) as propriedades centrais desse tipo de comportamento.

O poder de abarcar um vasto domínio de fenômenos operantes com um mecanismo simples que roda sobre um conjunto de parâmetros com valores fixos - e o fato de que ela faz isso a partir de uma arquitetura que pode ser facilmente expandida -, faz da máquina-MPR uma plataforma útil para a integração de teorias. À medida que outros pesquisadores enriquecerem o framework com novos módulos, ele poderá ajudar a elucidar como diferentes aspectos do comportamento operante interagem uns com os outros, pavimentando a transição de uma análise do comportamento para uma síntese comportamental.

Finalmente, o software de código aberto que implementa a máquina-MPR é disponibilizado para os interessados em contribuir com a evolução da arquitetura.

Palavras-chave: MPR, modelos, simulação, memória, excitação, timing, probabilidade. 



\begin{abstract}
Bittar, E. G. (2017). From behavior analysis to behavioral synthesis: Integrating models on the grounds of a computational architecture ( $\mathrm{Ph}$. D. Thesis). Departamento de Psicologia, Faculdade de Filosofia, Ciências e Letras de Ribeirão Preto, Universidade de São Paulo, Ribeirão Preto.
\end{abstract}

The basic models of MPR are used as the building blocks of a stochastic machine that simulates operant responding. The MPR-machine is then tested under a wide variety of experimental conditions, and proves its ability to produce realistic (a) IRT distributions, (b) within-session patterns of responding, and (c) relations between reinforcement rate and response rate under interval and ratio schedules. In another set of experiments, the model show realistic emergent properties and reproduces well known multiple schedule phenomena, such as (d) behavioral contrast and (e) extinction deceleration - all of them beyond the original reach of MPR.

In the last chapter of the study, the MPR-machine is embodied with a model of temporal control. The new configuration, named $t \mathrm{MPR}$, proves itself able to simulate (f) the timing behavior that arises under predictable interval schedules as well as $(\mathrm{g})$ the central properties of this behavior.

The power to account for a vast domain of operant behavior phenomena with a simple mechanism that runs on a fixed set of parameter values - and the fact that it does so based on an architecture that can be easily expanded to accommodate new models - makes the MPRmachine a useful platform for theory integration. As other researchers enrich the framework with new modules, it may help to elucidate how different aspects of operant behavior interact with one another, paving the transition from a behavior analysis to a behavioral synthesis.

Finally, open source software that implements the MPR-machine is provided for those interested in contribute to the architecture evolution.

Keywords: MPR, models, simulation, memory, arousal, timing, probability. 



\section{LISTA DE FIGURAS}

Figura 1. A máquina-MPR

Figura 2. Comparação das distribuições de IRT produzidas pela máquina-MPR e por ratos reais (Bittar, 2010) respondendo sob VI 30-s.

Figura 3. Responder intra-sessão sob vários esquemas VI, agregados sobre as últimas sessões em que cada condição esteve em efeito. O Painel A exibe dados de seis ratos (Bittar, 2010), enquanto o Painel B apresenta os dados gerados pela máquina-MPR. As curvas foram desenhadas pela Equação 2, juntamente com a Equação 6, com as estimativas dos parâmetros dadas pela Tabela 1. As configurações da máquina são discutidas no texto. 46

Figura 4. Taxa de resposta em função da taxa programada de reforçamento sob diferentes esquemas VI.

Figura 5. Valor final de $C$, agregado sobre as últimas 50 sessões em cada condição. A linha contínua horizontal representa a média dos pontos de dados (0.36), enquanto a linha pontilhada representa a estimativa de Killeen (1994) para $\rho$ sob esquemas VI (1/3). 48

Figura 6. Taxa de resposta em função do critério de reforçamento $(N)$ sob diferentes esquemas FR. A taxa de saciação $(\xi)$ foi variada entre condições. As curvas foram desenhadas pela Equação 21, com as estimativas dos parâmetros dadas na Tabela 2.

Figura 7. Taxas de resposta da máquina-MPR sob um esquema múltiplo de reforçamento. Das sessões 0 a 10, ambos os componentes entregavam reforçadores em VI 20-s. Das sessões 11 a 20, um componente ("variável”) foi alterado para extinção, enquanto o outro (“constante") permaneceu em VI 20-s. Das sessões 21 a 30, ambos os componentes voltaram para VI 20-s.

Figura 8. Dinâmica intra-sessão da excitação em uma sessão de linha de base (mult VI 20-s VI 20-s) e uma de contraste (mult VI 20-s EXT). O segundo componente (que foi alterado para EXT durante a sessão de contraste) está representado pelas barras cinzas. 
Figura 9. Padrões intra-sessão do responder no componente constante nas condições de linha de base (círculos preenchidos) e de contraste (círculos abertos). Os painéis de cima mostram os resultados para contraste positivo, e os de baixo para contraste negativo. A coluna da direita mostra dados de pombos reais (McSweeney et al., 2004), enquanto a da esquerda foi gerada pela máquina-MPR em um procedimento idêntico. 67

Figura 10. Taxas de resposta em um dos componentes de um esquema múltiplo durante sucessivas sessões de extinção. Os círculos preenchidos representam a condição na qual o segundo componente foi associado a VI 20 -s, enquanto os triângulos abertos representam a condição na qual o segundo componente também era um esquema de extinção. Os dados estão expressos como proporções da linha de base (Sessão 0). 69

Figura 11. Componentes e arquitetura da LeT. Um estímulo como comida funciona como um marcador temporal, iniciando uma propagação de ativação ao longo dos estados comportamentais. A ativação de cada estado, multiplicada pelo peso da associação com a resposta operante, determina sua força. A aprendizagem ocorre através da mudança sistemática dos pesos.

Figura 12. A máquina-MPR mesclada com uma versão da LeT. 80

Figura 13. Distribuição das respostas simuladas da máquina- $t$ MPR em função do tempo desde o último reforçador em diferentes esquemas FI. 82

Figura 14. Proporção da taxa de resposta terminal em função do tempo relativo dentro do intervalo em diferentes esquemas FI. Os dados foram gerados pela máquina- $t$ MPR. 83

Figura 15. Taxas de resposta em função das taxas de reforçamento sob diferentes esquemas FI. Os dados foram gerados pela $t$ MPR, e a curva é a hipérbole clássica de Herrnstein (1970). 


\section{LISTA DE TABELAS}

Tabela 1. Estimativas dos parâmetros da Equação 2 quando aplicada a dados intra-sessão de ratos (Bittar, 2010) e da máquina-MPR. O parâmetro $\delta$ é dado em segundos, enquanto os valores de $\mu$ são dados em minutos. 45

Tabela 2. Estimativas dos parâmetros da Equação 21 quando aplicada aos dados simulados de FR pela máquina-MPR. O parâmetro $\delta$ é dado em segundos, enquanto $a$ é dado em minutos. 



\section{SUMÁRIO}

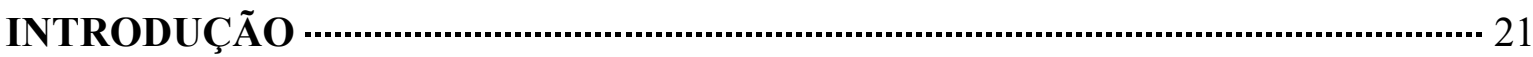

\section{CAPÍTULO 1: Os Fundamentos Matemáticos}

1. Princípios Matemáticos do Reforçamento …………………………………….... 25

2. Derivação da MPR a partir de Máquinas Estocásticas ………………………...... 26

3. A Dinâmica da Excitação ……………………............................................... 28

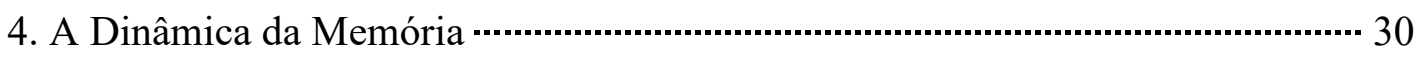

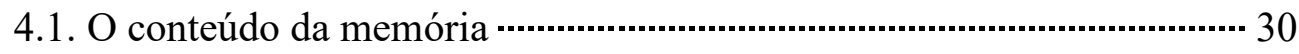

4.2. O modelo pré-assintótico de Killeen (1994) ……………………….... 31

4.3. Uma abordagem estocástica de $C$ …………………………………. 33

\section{CAPÍTULO 2: A Máquina-MPR}

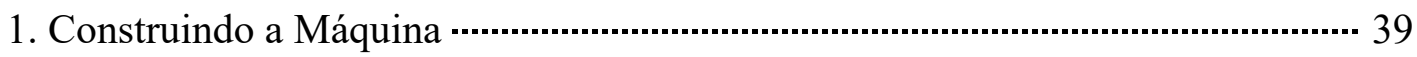

2. Rodando a máquina …………………………….......................................... 42

2.1. Experimento 1: Esquemas de intervalo variável ……………………... 43

2.2. Experimento 2: Esquemas de razão fixa ……………………………... 48

3. Discussão: Sobre as Limitações dos Modelos Finais da MPR …………............. 50

3.1. Aplicando a MPR a dados VI intra-sessão ………………................. 51

3.2. Aplicando a MPR a dados médios de sessões FR …………………..... 52

\section{CAPÍTULO 3: Adicionando Mais Engrenagens}

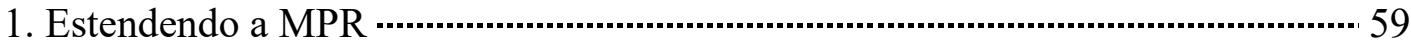

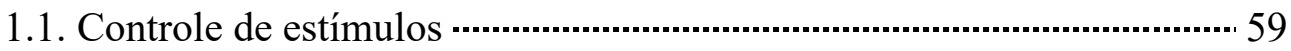

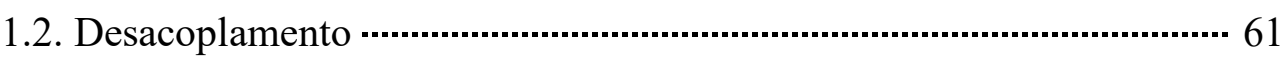

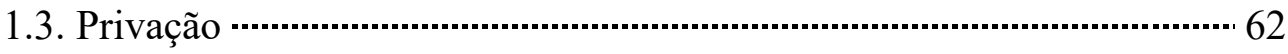

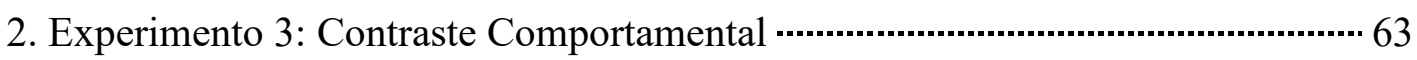

3. Experimento 4: Contraste e Responder Intra-Sessão ………………………….... 66

4. Experimento 5: Extinção sob Esquemas Múltiplos …………………………...... 68

CAPÍTULO 4: Controle por Esquemas e Timing: Avançando para a Integração de Teorias

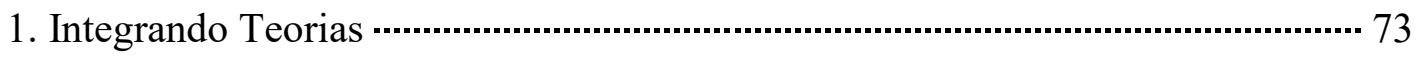

2. Temporizando a Máquina-MPR ……............................................................. 74

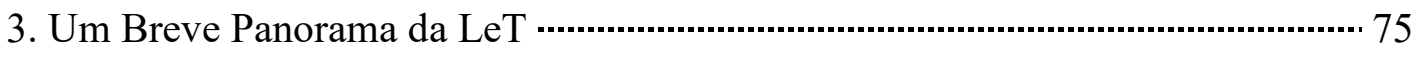

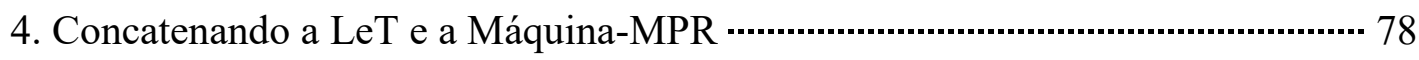

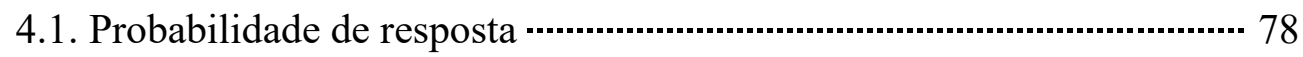

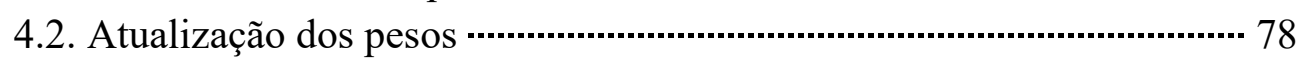

5. Reconstruindo a Máquina …….......................................................................... 79

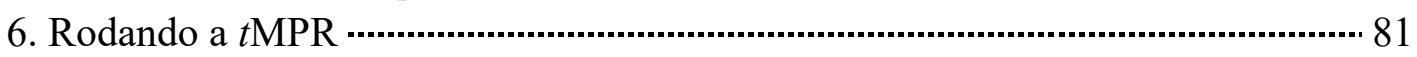

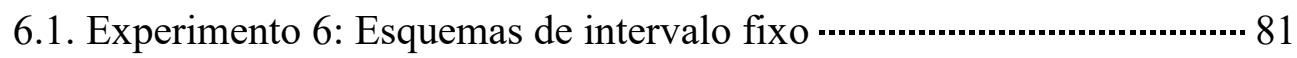

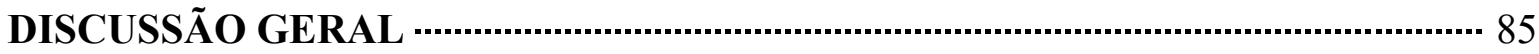

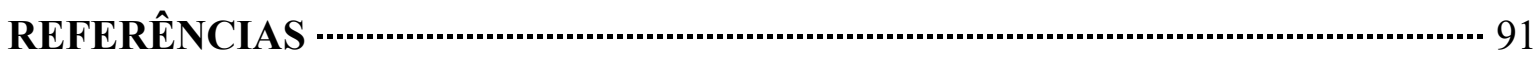

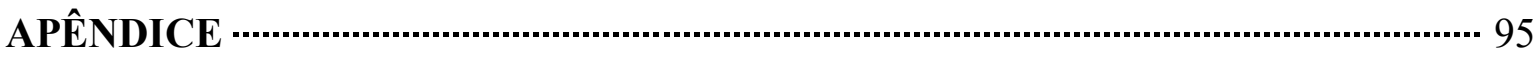





\section{INTRODUÇÃO}

Staddon e Bueno (1991) introduziram um artigo sobre modelos matemáticos com uma citação interessante do físico William Thompson, que diz:

Nunca me satisfaço até conseguir criar um modelo mecânico de algo. Se consigo criar um modelo mecânico, consigo entender. Se não consigo criar um modelo mecânico completo, não consigo entender [...] (William Thompson, 1884, pp. 270-271)

Modelos mecânicos são, de fato, ferramentas muito poderosas de investigação científica. Eles podem capturar o funcionamento essencial de um sistema enquanto desconsideram partes e variáveis irrelevantes. Ao fazer isso, oferecem insights claros acerca dos fenômenos que buscamos compreender.

Modelos mecânicos também podem nos ajudar a melhorar nossas teorias. Se uma teoria pode ser traduzida em um mecanismo, a comparação entre o comportamento do mecanismo e o comportamento do sujeito real será um teste interessante da teoria. O modelo e o sujeito devem ter comportamentos similares sob condições similares - de outra forma, as premissas do modelo são evidentemente falsas. Se similaridade for observada, o modelo deve ser testado sob novas circunstâncias até que uma divergência seja encontrada. O mecanismo é revisado e a investigação prossegue. Idealmente, levaremos nosso modelo mecânico até o ponto em que seu comportamento é indistinguível do comportamento do nosso sujeito.

Neste estudo, desenvolvemos um mecanismo que simula o responder operante livre sob diversos esquemas de reforçamento e condições experimentais. As premissas do modelo vêm de uma teoria do comportamento chamada Princípios Matemáticos do Reforçamento (MPR, na sigla em inglês; deste ponto em diante, toda menção à MPR é uma referência a Killeen, 1994). No Capítulo 1, a MPR é apresentada, suas relações com máquinas estocásticas são exploradas e a dinâmica de seus dois conceitos centrais (excitação e acoplamento) é discutida. No Capítulo 2, a máquina-MPR é desenvolvida e seu comportamento é comparado com o comportamento dos sujeitos que ela tenta emular. Em seguida, os dados simulados pela máquina são usados para discutir a adequação dos modelos finais da MPR. No Capítulo 3, demostramos como a máquina-MPR pode ser enriquecida com engrenagens adicionais para abranger fenômenos além do escopo para o qual ela foi originalmente desenvolvida. Por fím, para explorar completamente a utilidade da máquina-MPR como uma plataforma para integração de teorias, o Capítulo 4 dá um passo além, dotando a máquina de um módulo completo de controle temporal. 
Na discussão final, a contribuição da máquina-MPR à integração de teorias é analisada, e possíveis caminhos para aqueles interessados em estender sua arquitetura são sugeridos. 
CAPÍTULO 1

Os Fundamentos Matemáticos 


\section{Princípios Matemáticos do Reforçamento}

Killeen (1994) postulou que o comportamento é impulsionado pela excitação, direcionado pelo acoplamento e limitado pelo tempo. Ele também ofereceu descrições matemáticas de como essas forças interagem para produzir comportamento operante sob vários esquemas de reforçamento. A teoria resultante, chamada Princípios Matemáticos do Reforçamento, é capaz de prever e explicar com sucesso o responder sob uma ampla variedade de condições experimentais (e.g., Avila et al., 2009; Bizo, Kettle \& Killeen, 2001; Bradshaw \& Killeen, 2012; Killeen, 1994; Killeen \& Sitomer, 2003; Kleen et al., 2006; Sanabria et al., 2008).

A equação principal da MPR postula que:

$$
B=\frac{C A}{\delta(A+1)}
$$

onde $B$ é a taxa de resposta, $\delta$ é o tempo necessário para a emissão de uma única resposta e $A$ é a excitação do organismo (uma medida da taxa na qual respostas de diferentes tipos são eliciadas pelos incentivos). O parâmetro $C$, denominado coeficiente de acoplamento, representa o grau no qual as respostas e reforçadores são associados na memória de curto prazo do sujeito. Como veremos, esse coeficiente também pode ser interpretado como a proporção da excitação direcionada à emissão de respostas-alvo. É importante notar que, independentemente do quanto a excitação aumenta, a Equação 1 impõe um teto de $C / \delta$ para a taxa de respostas.

Buscando uma aplicação da MPR ao responder intra-sessão, Bittar et al. (2012) sugeriu um modelo revisado de como a excitação se acumula e se dissipa ao longo de uma sessão experimental. Nesse modelo revisado, a excitação é tomada como uma medida do estado eliciado no organismo pelos incentivos sucessivos, e não como uma medida da taxa na qual respostas (alvo ou não) são eliciadas pelos mesmos incentivos. A excitação como estado (representada por $A^{\prime}$ ) é limitada a valores entre 0 e 1 , onde 0 representa nenhuma excitação e 1 representa a excitação máxima suportada pela biologia do organismo. Bittar et al. (2012) demonstrou que, ao reinterpretamos a excitação como um estado, a equação fundamental da MPR pode ser reescrita como

$$
B=\frac{A^{\prime} C}{\delta}
$$


A Equação 2 é simples e intuitiva. Aqui, a relação entre os princípios da MPR é claramente demonstrada. A taxa de resposta é diretamente proporcional ao estado de excitação $\left(A^{\prime}\right)$ e ao acoplamento $(C)$, e inversamente proporcional ao tempo requerido para a emissão de uma resposta $(\delta)$. Quando a excitação é máxima $\left(A^{\prime}=1\right)$ e o acoplamento é máximo $(C=1)$, devemos esperar que a taxa de resposta atinja o seu teto $(1 / \delta)$.

Embora diferentes na forma de apresentação, as Equações 1 e 2 são, de fato, equivalentes. Bittar et al. (2012) obteve a versão de estado da excitação ( $A^{\prime}$ ) multiplicando a excitação como taxa $(A)$ por $1-A^{\prime}$ (um fator representando a distância da excitação ao seu teto). Em outras palavras, $A^{\prime}=A\left(1-A^{\prime}\right)$. Resolvendo isso para $A^{\prime}$ resulta em uma equação que mapeia a "excitação como estado" a partir da "excitação como taxa":

$$
A^{\prime}=\frac{A}{A+1}
$$

Ao inserir a Equação 3 na Equação 2, voltamos à Equação 1.

\section{Derivação da MPR a partir de Máquinas Estocásticas}

A Equação 2 pode ser derivada de uma conceituação do organismo como uma máquina estocástica cíclica simples. Como Killeen et al. (2002) a concebeu, essa máquina estocástica cíclica é um mecanismo conceitual com um timer em seu centro. O timer corre de 0 a $T$, quando a máquina emite uma resposta com probabilidade $p$. O timer é então reiniciado e um novo intervalo se inicia. Se $T=\delta$ e $p=A^{\prime}$, a máquina gerará respostas em uma taxa $A^{\prime} / \delta$. Se $C$ for reinterpretado como a probabilidade de cada resposta ser uma resposta-alvo, então as respostas-alvo serão emitidas em uma taxa $A^{\prime} C / \delta$, como postulado pela Equação 2. Quando $A^{\prime}=C=1$ podemos ter certeza de observar uma resposta-alvo no final de cada ciclo, e a taxa de respostas atinge o seu teto $(1 / \delta)$. Quando os incentivos se tornam menos efetivos (i.e., $A^{\prime}$ se reduz) ou as contingências se afrouxam (i.e., $C$ se reduz), a probabilidade de uma resposta-alvo ser emitida ao fim de cada ciclo se reduz, e a taxa de respostas cai. Essa máquina é provavelmente a implementação mais simples possível da MPR como um modelo mecânico do comportamento operante, e é capaz de simular o responder em um nível molar de análise. Sua simplicidade, no entanto, acarreta uma limitação importante: a máquina produz apenas intervalos entre respostas (IRTs) que são múltiplos de $\delta$ - o que, naturalmente, é muito irrealista. 
Agora, considere uma máquina equipada com um gerador que emite respostas a uma taxa $\lambda$. Se cada resposta tem duração de $\delta$ segundos, o IRT médio será $1 / \lambda+\delta$ e a taxa de resposta média será a recíproca do IRT médio, dada por $\lambda /(1+\delta \lambda)$. Se definirmos $\lambda=A / \delta$ e considerarmos que apenas uma proporção $C$ das respostas emitidas serão contadas como respostas-alvo, então $B=\frac{C A}{\delta(A+1)}$, e nós retornamos à Equação 1. Como as respostas são emitidas de acordo com um processo de Poisson, e como a emissão de cada resposta bloqueia a emissão de novas respostas por $\delta$ segundos, Killeen et al. (2002) chamou essa formulação de modelo Poisson refratário.

Dado que a excitação do organismo $(A)$ é proporcional à taxa de reforçamento, $\mathrm{o}$ modelo Poisson refratário prevê uma relação hiperbólica entre a taxa de respostas e a taxa de reforçamento. Nisso, como Killeen et al. (2002) observou, o modelo é diretamente relacionado às teorias molares do responder operante (e.g., Herrnstein, 1970, 1974). No nível molecular, o modelo produz IRTs com uma distribuição exponencial dada por $\lambda e^{-\lambda t}$, que é consistente com dados de sujeitos experimentais típicos como ratos e pombos (Killeen et al., 2002). É notável que um mecanismo tão simples possa construir uma ponte tão direta entre medidas molares e moleculares do responder operante.

Se os parâmetros que regulam o funcionamento da máquina refratária Poisson são mantidos constantes, o sistema produz um fluxo estável de respostas do momento em que é ligado até o momento em que é desligado. No entanto, esse fluxo estável quase nunca é observado em sujeitos reais. O comportamento de ratos e pombos é dinâmico tanto na fase de aquisição quanto na fase assintótica da maioria dos procedimentos livre-operantes. Mudanças na taxa de resposta durante a fase assintótica refletem variações na motivação ao longo de uma sessão, e podem ser capturadas por um modelo dinâmico de $A$ (Bittar et al., 2012; Killeen, 1995; Killeen, Hanson \& Osborne, 1978). Mudanças na taxa de resposta durante a fase de aquisição refletem processos de aprendizagem, e podem ser capturadas por um modelo dinâmico de $C$ (Killeen, 1994).

Nas seções a seguir, modelos dinâmicos de $A$ e $C$ são apresentados. A máquina-MPR será construída no próximo capítulo, quando esses modelos dinâmicos serão embutidos na máquina Poisson refratária descrita acima. 


\section{A Dinâmica da Excitação}

Incentivos impulsionam o comportamento - este é o primeiro princípio da MPR (Killeen \& Sitomer, 2003). Eles fazem isso eliciando excitação que é prontamente convertida em atividade. No entanto, a relação entre a excitação atual de um organismo e suas condições atuais de incentivo não é direta. Em primeiro lugar, como Killeen et al. (1978) demonstrou, a excitação eliciada por incentivos sucessivos se acumula, levando o organismo a um estado de ativação que nenhum incentivo sozinho seria capaz de produzir. Em segundo lugar, como Bittar et al. (2012) demonstrou, a excitação acumulada se dissipa lentamente, mesmo depois que os incentivos perdem completamente seus efeitos excitatórios por processos como saciação ou habituação. Portanto, a excitação tem inércia inicial (Killeen et al., 1978) e final (Bittar et al., 2012).

Essas considerações podem ser capturadas por um simples par de equações. No momento em que um novo incentivo é apresentado, o acúmulo de excitação pode ser representado por (Bittar et al., 2012):

$$
A^{*}=A+Q e^{\frac{-n}{\xi}}
$$

onde $A$ é a excitação atual, $Q$ representa o impulso de excitação eliciado pelo incentivo e $A^{*}$ é a excitação que resulta dessa soma. O fator exponencial que pondera o parâmetro $Q$ representa os efeitos da saciação. À medida que o número de incentivos previamente consumidos $(n)$ aumenta em relação à constante de saciação $(\xi)$, o impulso de excitação eliciado por cada novo incentivo progressivamente decresce de maneira exponencial.

Quando nenhum incentivo é apresentado, a excitação decai exponencialmente ao longo do tempo (Killeen et al., 1978):

$$
A_{t}=A_{0} e^{\frac{-t}{\mu}}
$$

onde $A_{0}$ representa a excitação inicial, $t$ representa a passagem do tempo e $\mu$ é a constante temporal do decaimento da excitação.

Bittar et al. (2012) usou esse simples par de equações como o bloco construtivo de uma equação complexa de forma fechada, que descreve como a excitação se acumula e se 
dissipa enquanto incentivos são apresentados e consumidos no decorrer de uma sessão experimental. A equação para a excitação como estado $\left(A^{\prime}\right)$ estabelece que

$$
A_{t}^{\prime}=\frac{Q e^{\frac{1}{R \mu}+\frac{1}{\xi}}\left(-1+e^{\frac{-t}{\mu}+\frac{R t}{\xi}}\right)}{-Q e^{\frac{1}{R \mu}+\frac{1}{\xi}}+e^{\frac{R t}{\xi}}\left[e^{\frac{1}{\xi}}+e^{\frac{1}{R \mu}}\left(-1+Q e^{\frac{-t}{\mu}+\frac{1}{\xi}}\right)\right]},
$$

onde $R$ é a taxa de reforçamento.

Inserida no framework geral da MPR (Equação 2), esse modelo dinâmico é capaz de prever variações intra-sessão no responder operante em condições experimentais que variam tamanho do incentivo, taxa de incentivo e capacidade do organismo (Bittar et al., 2012).

Por uma questão de simplicidade, esse modelo da dinâmica da excitação foi aplicado apenas a dados de esquemas de intervalo variável (VI). A função de feedback desses esquemas prevê pequenas variações na taxa de reforçamento $(R)$ ao longo de grandes variações na taxa de resposta $(B)$, permitindo-nos assumir a taxa de reforçamento como invariante (Ettinger, Reid, \& Staddon, 1987; Killeen, 1994). Aplicar a Equação 6 a outros esquemas, por outro lado, não é algo tão simples e direto. Para esquemas de razão, por exemplo, $R$ deve ser substituído por $B / N$, onde $N$ é o requisito do esquema. Depois, a Equação 6 deve ser inserida na Equação 2 e resolvida para $B$. A equação resultante, infelizmente, é impraticavelmente complexa, já que contém um loop de feedback: a taxa de resposta determina a taxa de reforçamento (por cumprimento do requisito do esquema) ao mesmo tempo em que a taxa de reforçamento determina a taxa de resposta (por eliciação de excitação). Buscando um modelo de dinâmica motivacional, Killeen (1995) chegou ao mesmo beco sem saída.

Aqui, não estamos tentando obter uma equação de forma fechada que descreva esse loop de feedback entre a taxa de resposta e a taxa de reforçamento em esquemas de razão e outros relacionados. Em vez disso, nosso objetivo é construir um mecanismo que implemente a MPR e simule o responder operante. Com isso, poderemos colocar a complexidade da Equação 6 de lado e trabalhar apenas com seus blocos construtivos básicos, colocando as Equações 4 e 5 dentro da máquina e deixando as funções de feedback de esquema operarem no ambiente virtual onde o mecanismo reside. A interação resultante entre a máquina e seu ambiente poderá ser testemunhada simplesmente iniciando a operação do sistema. 


\section{A Dinâmica da Memória}

\subsection{O conteúdo da memória}

Killeen (1994) introduziu seu artigo seminal da MPR reconhecendo que "os efeitos de um reforçador não são limitados apenas à resposta que imediatamente o precede". Em vez disso, os reforçadores atuam sobre a sequência completa de respostas que conduziu ao reforçamento, da forma que o sujeito é capaz de recordá-la. Em outras palavras, o que está sendo reforçado não é a resposta como o experimentador a define, mas a "resposta estendida" como a memória do sujeito a representa.

Mas como podemos saber o conteúdo da memória de nosso sujeito? Para responder essa questão espinhosa, Killeen (1994) primeiramente assumiu que a memória é dirigida por eventos (em oposição a dirigida por tempo). Isto significa dizer que o efeito de um reforçador atrasado sobre uma resposta específica não é reduzido porque o traço de memória para essa resposta decai ao longo do tempo, mas porque as respostas interinas que ocorrem durante o atraso rebaixam a memória da resposta-alvo, absorvendo a maior parte dos efeitos que o reforçador tem a oferecer. Em segundo lugar, ele ofereceu o processo simples da média móvel exponencialmente ponderada (EWMA, na sigla em inglês) como um modelo de atualização da memória:

$$
\begin{aligned}
& M_{n}=\beta y_{n}+(1-\beta) M_{n-1}, \\
& 0 \leq \beta \leq 1,
\end{aligned}
$$

onde $M_{n}$ é o conteúdo da memória no momento em que um novo evento é introduzido, $M_{n-1}$ é o conteúdo anterior, $y_{n}$ é o atributo desse novo evento e $\beta$ é o parâmetro que determina o peso do evento mais recente. Quando $\beta=1$, a memória é totalmente determinada pelo último evento, e o passado não é importante. Quando $\beta$ se aproxima de 0 , o passado pesa mais, e a memória se torna mais conservativa.

Consistentemente com a premissa de que a memória é dirigida por eventos, a Equação 7 deve ser iterada sempre que um novo evento ocorre. Como exemplo, assumamos $y=1$ para respostas-alvo, $y=0$ para respostas não alvo, $M_{0}=0$ e $\beta=0.25$. Se a primeira resposta em uma sequência é uma resposta-alvo, o conteúdo da memória após esse evento será $M_{1}=0.25$. Se a segunda resposta na sequência for uma resposta não alvo, ela entrará na memória com 
peso $\beta$ ao mesmo tempo em que rebaixará a memória prévia por um fator de $1-\beta$. Logo, $M_{2}=0.1875$. Uma nova resposta-alvo na posição 3 da sequência vai iterar a Equação 7 mais uma vez, aumentando a representatividade desta classe operante na memória $\left(M_{3}=0.39\right)$.

Uma premissa importante da MPR é que o consumo de um reforçador geralmente desloca todo o responder prévio para fora da memória, resetando-a para o próximo trial (mas veja Killeen, 1994, e Killeen \& Sitomer, 2003, para uma discussão sobre deleção incompleta). Uma consequência dessa premissa é que taxas de reforçamento mais altas podem manter menos respostas-alvo do que taxas de reforçamento mais baixas. Se nosso sujeito está respondendo sob reforço contínuo (CRF), por exemplo, cada reforçador irá contatar apenas uma resposta-alvo na memória de curto prazo, que receberá uma proporção $\beta$ do efeito total do reforçador. Quando a taxa de reforçamento é reduzida, mais respostas-alvo têm a oportunidade de entrar na memória a cada trial, aumentando a proporção do efeito total do reforçador absorvida pela classe operante de interesse. Killeen (1994) incorporou esse insight na formulação assintótica da MPR, tornando $M$ o principal determinante de $C$ - o coeficiente de acoplamento que aparece nas Equações 1 e 2.

\subsection{O modelo pré-assintótico de Killeen (1994)}

A ponderação exponencial dos eventos passados expressa na Equação 7 também foi aplicada por Killeen (1994) para explicar como o comportamento muda de seu estado inicial amórfico para o estado assintótico descrito pelas equações canônicas da MPR. Nesse modelo pré-assintótico, uma trajetória é definida como um fluxo de respostas-alvo e não alvo culminando com a apresentação de um reforçador. No início do condicionamento, a probabilidade de uma resposta-alvo ocorrer em qualquer posição da trajetória é baixa e constante. Quando um reforçador é apresentado, a probabilidade de uma resposta ocorrer na mesma posição $i$ da trajetória no próximo trial $\left(p_{i}\right)$ é aumentada em uma função de seu peso (w) na memória no momento do reforçamento, de modo que

$$
p_{i}^{\prime}=p_{i}+w_{j}\left(1-p_{i}\right)
$$

onde $p_{i}{ }^{\prime}$ é a probabilidade atualizada e $\left(1-p_{i}\right)$ é um fator representando a distância da probabilidade atual $\left(p_{i}\right)$ ao teto. A fórmula para o peso $w$ pode ser derivada da Equação 7 . 
Ela atribui um peso $\beta$ para a última resposta (aquela que produziu o reforçador), $\beta(1-\beta)$ para a penúltima, $\beta(1-\beta)^{2}$ para a antepenúltima, e assim por diante. Por indução,

$$
w_{j}=\beta(1-\beta)^{j-1},
$$

onde $j$ é a distância da resposta ao reforçador mais 1.

Para simplificar a análise, Killeen (1994) dividiu os eventos da trajetória entre respostas-alvo e não alvo. As probabilidades dessas classes são complementares, de modo que aumentar a probabilidade das resposta-alvo significa reduzir a probabilidade das respostas não alvo na mesma posição. Reinterpretando $p_{i}$ como a probabilidade de uma resposta-alvo na posição $i$, segue-se das considerações acima que

$$
p_{i}^{\prime}=w_{j} y_{i}+\left(1-w_{j}\right) p_{i}
$$

onde $y=1$ para respostas-alvo e $y=0$ para respostas não alvo.

Killeen (1994) implementou a equação acima em uma simulação computacional tornando o reforçamento contingente à $16^{\mathrm{a}}$ resposta-alvo registrada em cada trial (i.e., razão fixa [FR] 16). Essa contingência garantiu que à última resposta-alvo da trajetória fosse sempre atribuída um peso $\beta$, enquanto o peso de uma resposta não alvo nunca poderia exceder $\beta(1-\beta)$. O efeito desse viés foi aumentar a probabilidade de respostas-alvo no final da trajetória desde os trials iniciais. Com o treino, esse efeito se propagou para cada posição da trajetória, tornando as respostas não alvo mais escassas a cada novo trial.

Na condição idealizada na qual cada resposta na trajetória é uma resposta-alvo, o conteúdo da memória no momento em que um reforçador é produzido em um esquema FR é dado por

$$
M_{N}=1-(1-\beta)^{N},
$$

onde $N$ representa a razão do esquema. O coeficiente de acoplamento para os esquemas FR $\left(C_{F R}\right)$, por sua vez, é dado por

$$
\begin{aligned}
& C_{F R}=\rho M_{N}, \\
& 0 \leq \rho \leq 1,
\end{aligned}
$$


onde $\rho$, a constante de acoplamento, é a proporção de respostas-alvo na trajetória comportamental. A aprendizagem, como vimos no modelo pré-assintótico acima, é representada por uma mudança gradual em $\rho$ ao longo de reforçadores sucessivos. À medida que o treino avança, $\rho \rightarrow 1$.

Uma compreensão cuidadosa das considerações acima revela que o modelo préassintótico apresentado aqui está em desacordo com a formulação estocástica da MPR previamente sugerida. Naquela formulação, para construir uma ponte entre a máquina Poisson refratária e a Equação 1, foi necessário interpretar o coeficiente de acoplamento $C$ como a probabilidade de uma resposta-alvo em cada ponto da trajetória. No entanto, ao formular seu modelo de aprendizagem, Killeen (1994) dissociou o coeficiente de acoplamento $(C)$ da noção de probabilidade de resposta-alvo $(\rho)$. De acordo com o modelo pré-assintótico, depois de sucessivos trials de treino sob um esquema CRF, por exemplo, a probabilidade de uma resposta-alvo em qualquer ponto da trajetória $(\rho)$ tende a 1 . Ao mesmo tempo, como as Equações 11 e 12 nos dizem, o coeficiente de acoplamento $C$ se aproxima de $\beta$, impondo um teto de $\beta / \delta$ à taxa de resposta. Isto levanta algumas questões: se as respostas não alvo são tão escassas neste ponto do treino, o que impede a taxa de resposta de exceder esse teto? $\mathrm{O}$ que está ocorrendo com o tempo restante do animal? A taxa de resposta (ao menos a taxa de resposta corrente) não deveria ir a $1 / \delta$ à medida que a proporção de respostas não alvo na trajetória se aproxima de 0 ?

\subsection{Uma abordagem estocástica de C}

Para tornar a noção do coeficiente de acoplamento adequada a uma tradução da MPR em uma máquina estocástica, nós abandonaremos o modelo pré-assintótico da MPR e assumiremos que $C$ é simplesmente a probabilidade de uma resposta-alvo ser observada em qualquer posição da trajetória. ${ }^{1}$

Por outro lado, nos manteremos leais às premissas centrais de Killeen sobre o funcionamento da memória, abraçando a Equação 7 como determinante de $C$. Para fazer isso, nós primeiramente assumiremos $y=1$ para respostas-alvo e $y=0$ para respostas não alvo.

1. Ao introduzir seu modelo pré-assintótico, o próprio Killeen (1994) reconheceu que ele não era uma parte necessária da teoria da MPR. Abrindo a apresentação, ele escreveu que "o que se segue é um de muitos modelos possíveis, introduzido como base e prova de plausibilidade para o modelo assintótico, que é o foco primário deste artigo". 
Dessa forma, além de representar o conteúdo da memória, o parâmetro $M$ também representará a proporção dos efeitos do reforçador direcionada ao fortalecimento das respostas-alvo. Em cada trial, assumiremos que a proporção de respostas-alvo na trajetória $(C)$ equivale ao grau no qual essa classe operante foi fortalecida no trial anterior $(M)$. Então, podemos simplesmente permitir que $C$ acompanhe o valor reforçado de $M$ do último trial, de modo que

$$
C^{\prime}=M_{S R}
$$

onde $C^{\prime}$ é o valor atualizado de $C$ após o reforçamento e $M_{S R}$ é o conteúdo da memória no momento do reforçamento. Se, por exemplo, o organismo obtém um reforçador quando o conteúdo de sua memória é 0.5 , então a cada ponto da trajetória comportamental produzida no próximo trial a probabilidade de uma resposta-alvo também será de 0.5 .

É importante notar que, diferentemente do que possa parecer, a Equação 13 permite que a proporção de respostas-alvo no próximo trial seja muito diferente da proporção observada no último trial reforçado. Isto porque, como a Equação 7 nos mostra, $M_{S R}$ não é um retrato da proporção que levou ao reforçamento, mas a representação do sujeito da contribuição relativa de cada classe de resposta ao reforçamento. Com valores maiores para $\beta$, o peso atribuído à última resposta aumenta. Como a última resposta é geralmente a respostaalvo, valores maiores de $\beta$ levam a proporções correspondentemente maiores de respostasalvo no próximo trial.

Um problema da Equação 13 é que ela torna a aprendizagem irrealisticamente rápida. Sob reforço contínuo, por exemplo, será necessário apenas um trial de treino para que o comportamento atinja estabilidade assintótica. A Equação 13 também torna o comportamento instável, já que o responder em cada trial é extremamente sensível a variações aleatórias do responder no trial anterior. Nós podemos desacelerar a aprendizagem e aumentar a estabilidade assumindo que a memória no momento de cada reforçamento $\left(M_{S R}\right)$ contribui com apenas uma proporção $\omega$ às atualizações de $C$. Uma equação proximamente relacionada à Equação 7 pode oferecer um modelo para isso:

$$
\begin{aligned}
& C^{\prime}=\omega M_{S R}+(1-\omega) C, \\
& 0 \leq \omega \leq 1
\end{aligned}
$$


A Equação 14 será nosso modelo de como a probabilidade de respostas-alvo em cada trial acompanha a memória das trajetórias prévias. Valores maiores de $\omega$ implicam aprendizagem mais rápida e maior instabilidade de trial a trial. Quando $\omega=1$, a Equação 14 é reduzida à Equação 13.

A Equação 14 também pode ser compreendida como uma asserção sobre a relação entre as memórias de curto e longo prazo. Em linguajar cognitivo, é um modelo de como a memória de longo prazo das contingências em operação $(C)$ é afetada pela memória de curto prazo da última estratégia bem-sucedida $\left(M_{S R}\right)$. Nesse contexto, o parâmetro $\omega$ pode ser interpretado como a sensibilidade da memória de longo prazo a novas informações - uma medida grosseiramente relacionada à noção de inteligência do senso-comum. 
CAPÍTULO 2

A Máquina-MPR 


\section{Construindo a Máquina}

Concatenando toda a informação apresentada acima, podemos montar a primeira versão da máquina-MPR. A arquitetura geral desse mecanismo está representada como um fluxograma na Figura 1. Cada elemento na figura está numerado, para facilitar o referenciamento no texto. (É importante alertar que todas as expressões no diagrama devem ser interpretadas como comandos de programação computacional, e não como equações matemáticas. Logo, o sinal de igualdade $(=)$ deve ser entendido como um operador de atribuição, e não como um enunciado matemático. A expressão $y=1$, por exemplo, não é um enunciado de que $y$ é igual a 1 . Em vez disso, é um comando que atribui o valor 1 à variável $y$, independentemente do valor que estava previamente armazenado. Da mesma forma, o comando $y=1+y$ soma 1 ao valor atual de $y$ e depois armazena o resultado na variável $y$, sobrescrevendo o valor que estava previamente registrado.)

No núcleo da máquina-MPR existe um gerador de respostas, representado pelo Box 1 na Figura 1. Quando ativado, esse elemento aguarda $T$ segundos para emitir uma resposta. Como esse gerador tem uma oportunidade contínua para emitir a resposta, sua operação reflete um processo Poisson. Em consequência, o tempo $T$ que devemos esperar para observar uma resposta será uma variável randômica exponencialmente distribuída:

$$
T \sim \operatorname{Exp}(\lambda)
$$

onde $\lambda$ é a taxa de geração de respostas. Como discutido acima, também assumimos que $\lambda=A / \delta$. Isso implica que à medida que a excitação aumenta em relação à duração da resposta, as respostas são emitidas em uma taxa mais rápida, tornando os valores menores de $T$ mais prováveis.

Então, em resumo, o gerador de respostas faz o seguinte: (1) ele busca o valor armazenado na variável $A$ e o divide pelo valor armazenado na variável $\delta$, atribuindo o resultado à variável $\lambda$; e (2) ele usa o valor armazenado em $\lambda$ para gerar uma variável randômica exponencialmente distribuída que é atribuída à variável $T$. Nós então consideramos que uma resposta foi emitida no tempo $T$ e seguimos para o próximo passo.

O comando dentro do Box 2 deve parecer familiar. Ele é uma implementação da Equação 5, nosso modelo de decaimento da excitação. O gerador de respostas levou $T$ segundos para emitir uma resposta, e devemos assumir que a excitação decaiu ao longo desse 
intervalo. Nosso conhecimento da excitação do organismo deve ser atualizado, e esta é a tarefa realizada pelo segundo Box.

Após atualizar a excitação, chegamos ao Box 3. Este passo é essencial à máquina, posto que ele define se a resposta gerada é uma resposta-alvo ou não. Para fazer isso, assumimos $X$ como uma variável aleatória uniformemente distribuída com valor entre 0 e 1 . Depois, checamos se seu valor é menor ou igual a $C$-nosso coeficiente de acoplamento. Se $X>C$, tomamos a resposta gerada como não alvo e seguimos para o Box 4a. De outra forma, nós a tomamos como uma resposta-alvo e seguimos para o Box 4b. Em qualquer caso, o sistema pausa por um tempo equivalente à duração da resposta.

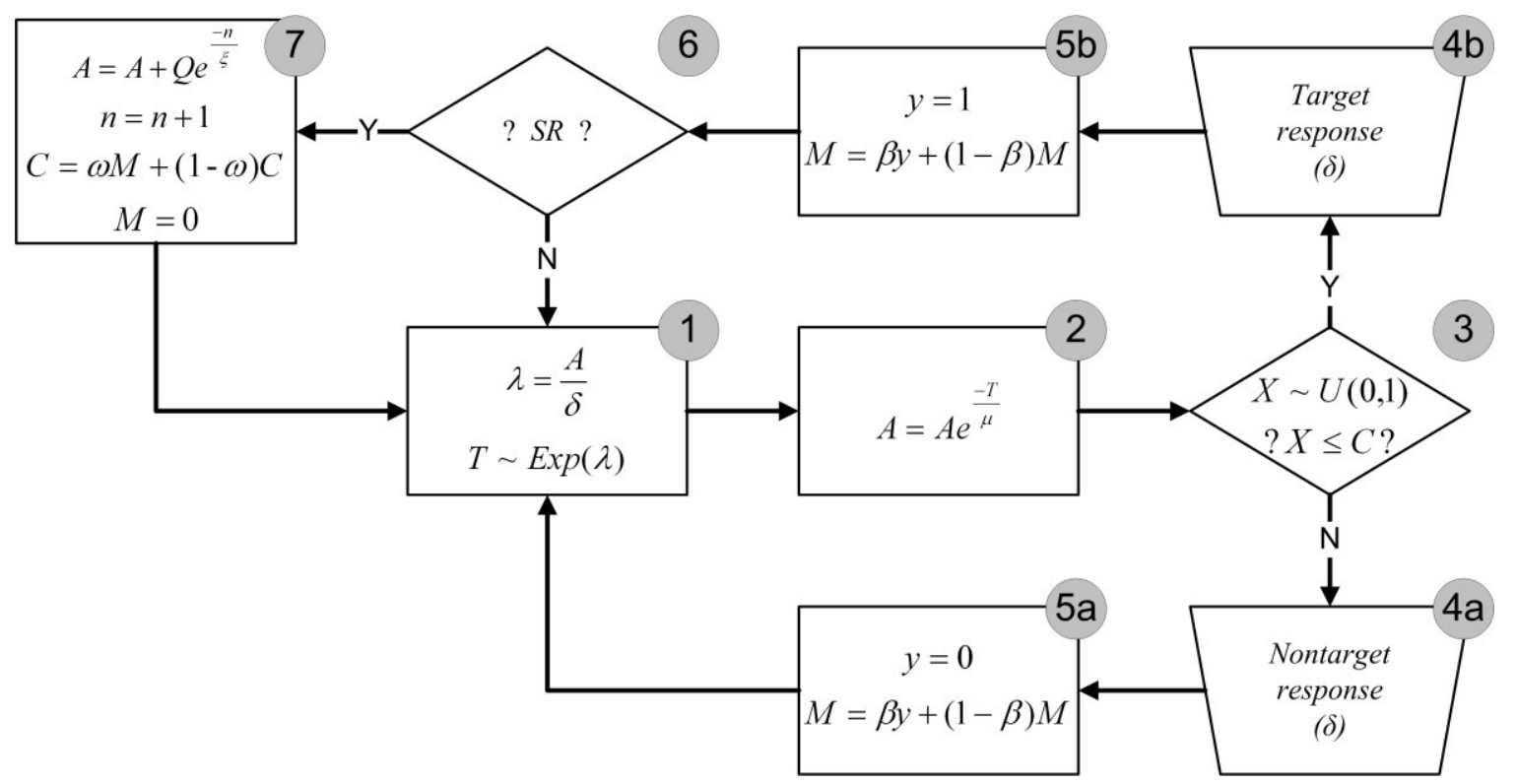

Figura 1. A máquina-MPR.

Na máquina apresentada aqui, assumimos que a duração de uma resposta não alvo é igual à duração de uma resposta-alvo $(\delta)$. Como vimos, isso faz com que o IRT médio seja $1 / \lambda+\delta$, o que permite uma ponte direta entre o comportamento de nossa máquina e a Equação 1. Se durações diferentes são atribuídas a cada classe, o IRT médio (considerando respostas-alvo e não alvo) se torna

$$
\frac{1}{B}=C\left(\frac{1}{\lambda}+\delta_{T}\right)+(1-C)\left(\frac{1}{\lambda}+\delta_{O}\right),
$$


onde $\delta_{T}$ é a duração de uma resposta-alvo e $\delta_{O}$ é a duração média de todas as outras respostas não registradas. A Equação 16 pode ser simplificada como

$$
\frac{1}{B}=\frac{1}{\lambda}+\delta_{O}+C\left(\delta_{T}-\delta_{O}\right)
$$

Resolvendo para a taxa de resposta $B$, e assumindo $\lambda=A / \delta_{T}$, concluímos que

$$
B=\frac{A}{\delta_{T}+A C \delta_{T}-A \delta_{O}(C-1)}
$$

Por outro lado, assumindo $\delta_{T}=\delta_{O}=\delta$, como fizemos na Figura 1, reduzimos a Equação 18 para

$$
B=\frac{A}{\delta(A+1)}
$$

Para obter a taxa de emissão das respostas-alvo, consideramos que apenas uma proporção $C$ das respostas emitidas pelo gerador pertencem à classe mensurada, multiplicando esse parâmetro pela Equação 19 - o que nos leva de volta à Equação 1. Uma conclusão interessante que se segue é que, se quisermos compreender os organismos como máquinas estocásticas, e se quisermos tomar a MPR como um modelo de seu comportamento, então uma premissa subjacente e necessária da teoria (como geralmente apresentada na forma de sua equação canônica) é que as respostas-alvo e não alvo são eventos de mesma duração.

Depois de aguardar $\delta$ segundos e notificar o ambiente virtual que uma resposta-alvo ou não alvo ocorreu, a máquina segue para o quinto passo. Este passo, representado pelos Boxes $5 a$ e 5 b da Figura 1, representa a codificação na memória da resposta que acabou de ser emitida. Trata-se da simples implementação da Equação 7, com $y=1$ para respostas-alvo e $y=0$ para respostas não alvo.

Para respostas não alvo, depois do quinto passo nós retornamos ao início (i.e., a ativação do gerador de respostas e a produção de uma nova resposta). Nosso ambiente não está programado para oferecer feedback para essa classe de respostas, e nada mais deve ocorrer. Todavia, no caso das respostas-alvo é possível que o ambiente responda ao evento com a apresentação de um reforçador (e.g., se um requisito do esquema foi completado). Consequentemente, após o Box 5 b nós seguimos para o Box 6 , que pergunta se um reforçador 
foi obtido ou não. Se não, voltamos ao primeiro passo. Em caso afirmativo, vamos para o Box 7.

Este último passo representa a reação do organismo ao reforçador. Essa reação é resumida em quatro comandos. O primeiro comando é uma implementação da Equação 4, nosso modelo de eliciação de excitação e de saciação. $O$ segundo comando incrementa a variável $n$, que registra quantos reforçadores já foram consumidos. O terceiro comando implementa a Equação 14, nosso modelo de como $C$ acompanha mudanças no último $M$ reforçado. $\mathrm{O}$ comando final reinicia $M$ de volta para 0 , implementando a noção de que o consumo de um reforçador apaga o conteúdo prévio da memória de curto prazo.

Em resumo, a máquina-MPR ilustrada na Figura 1 é uma máquina Poisson refratária construída sobre duas premissas: (1) a taxa pela qual as respostas são geradas é proporcional à excitação, e (2) a proporção dessas respostas que pertence à classe operante é uma função do grau no qual essa classe foi fortalecida no passado. Ademais, ela implementa (1) um modelo de decaimento da excitação, (2) um modelo de atualização da memória de curto prazo, (3) um modelo de eliciação de excitação, (4) um modelo de saciação e (5) um modelo de como a probabilidade de respostas-alvo depende de sua representação na memória nos episódios passados de reforçamento.

\section{Rodando a Máquina}

Para validar nossa máquina-MPR, precisamos checar se seu comportamento é realista ou não. Neste estágio inicial, ficaremos satisfeitos se a máquina provar sua capacidade de reproduzir quatro padrões bem conhecidos do responder operante amplamente encontrados na literatura: (1) a distribuição aproximadamente geométrica dos IRTs em bins de 0.5 segundos ou mais (e.g., Killeen et al., 2002), (2) os padrões monotônicos e bitônicos do responder operante intra-sessão (e.g., McSweeney, Hatfield, \& Allen, 1990; McSweeney \& Hinson, 1992; McSweeney, Roll, \& Weatherly, 1994), (3) a relação hiperbólica entre a taxa de resposta e de reforçamento sob esquemas VI (e.g., Bradshaw, Szabadi, \& Bevan, 1978; Catania \& Reynolds, 1968; Herrnstein, 1970; Heyman \& Monaghan, 1987), e (4) o decaimento linear da taxa de resposta à medida que o critério para o reforçamento $(N)$ aumenta sob esquemas de razão fixa (e.g., Bizo \& Killeen, 1997). A produção dos primeiros 
três padrões será testada no Experimento 1, enquanto o ultimo padrão será verificado no Experimento 2.

\subsection{Experimento 1: Esquemas de intervalo variável}

Para executar a máquina-MPR, primeiramente precisamos atribuir valores numéricos a cada um de seus parâmetros. Bittar et al. (2012) consistentemente encontrou $Q=.15$ para ratos e pombos, e este será o valor padrão para este parâmetro. Ele também encontrou valores para $\xi$ variando de 10.7 ao infinito. Pequenos valores para $\xi$ são geralmente encontrados sob altas taxas de reforçamento, indicando que a saciação está ocorrendo em ritmo rápido. Por outro lado, $\xi=\infty$ tende a ocorrer para baixas taxas de reforçamento, indicando que a saciação promovida por cada reforçador está se dissipando entre apresentações sucessivas, prevenindo qualquer saciação global de ocorrer. Um modelo de privação será desenvolvido mais adiante neste trabalho; por hora, iremos simular a recuperação da saciação atribuindo valores mais baixos para $\xi$ para esquemas mais ricos e valores mais elevados quando a taxa de reforçadores programados for baixa. Neste experimento específico, fixamos $\xi$ em 10, 30, $50 \mathrm{e}$ 100 para VI 15, 30, 60 e 120-s, respectivamente.

A constante temporal do decaimento da excitação $(\mu)$ foi estimada em 6 min em todas as condições estudadas por Bittar et al. (2012). Como esse também foi o valor encontrado por Killeen em vários estudos (Killeen et al., 1978; Killeen, 1995; Killeen, 1998), nós o adotamos como o valor padrão ao longo de todo o experimento. Fixamos $\beta=.18$ para permanecer no intervalo encontrado por Killeen (1994). A literatura também mostra que $\delta$ é geralmente mais baixo que $1 \mathrm{~s}$, com $.35 \mathrm{~s}$ como um valor representativo para pombos e $.5 \mathrm{~s}$ como um valor representativo para ratos (e.g., Bizo \& Killeen, 1997; Bittar et al., 2012; Killeen, 1994; Sanabria et al., 2008). Aqui, fixamos $\delta=.55$. Também fixamos $\omega=.15$ (diferentes valores para $\omega$ podem afetar a velocidade de aprendizagem e a estabilidade de um trial a outro, mas não afeta significativamente os dados de nosso interesse).

Como vimos, motivação e memória são processos dinâmicos. Assim, $A$ e $C$ sempre se alterarão no curso de cada sessão. No entanto, é necessário atribuir valores iniciais a essas variáveis. Para $A$, podemos assumir que a excitação experimentada sob cada esquema se torna condicionada ao contexto do experimento. Consequentemente, podemos deixar a excitação inicial em cada sessão refletir essa excitação contextual, que será maior sob esquemas ricos do 
que sob esquemas pobres. Aqui, fixamos o valor inicial de $A$ em $.4, .25, .15$ e .07 para VI 15, 30, 60 e 120-s, respectivamente. Por outro lado, fixamos $C=.3$ na primeira sessão de cada condição - um valor em acordo com a estimativa de Killeen (1994) para $\rho$ sob esquemas VI. Em sessões subsequentes, atribuímos inicialmente a $C$ o valor final que esse coeficiente assumiu ao final da sessão anterior - um procedimento que garante a transferência de aprendizagem de uma sessão a outra. Cada condição compreendeu 20 sessões, sendo 15 para treino (estabilização de $C$ ) e 5 para análise dos dados. Cada sessão durou 30 minutos.

As Figuras 2 a 4 exibem os resultados do experimento, sempre em comparação com dados reais de seis ratos, sob condições experimentais idênticas (Bittar, 2010; Bittar et al., 2012). As médias dos dados, tanto dos ratos simulados quanto dos reais, foram tomadas das últimas cinco sessões em que cada condição esteve em efeito. Podemos depreender das figuras que a máquina-MR foi capaz de simular precisamente o responder operante nos três níveis de análise.

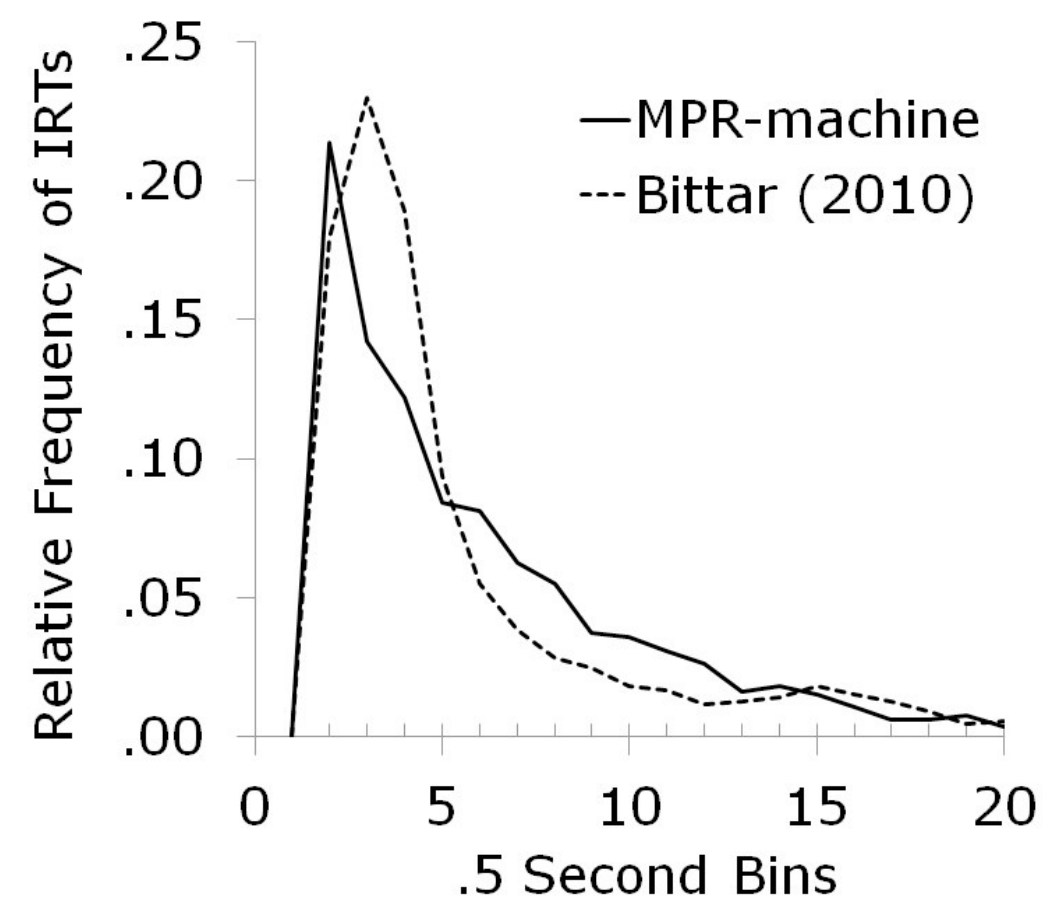

Figura 2. Comparação das distribuições de IRT produzidas pela máquina-MPR e por ratos reais (Bittar, 2010) respondendo sob VI 30-s. 
Parameters

\begin{tabular}{ccccccc} 
Subjects & Condition & $C$ & $\delta$ & $Q$ & $\mu$ & $\xi$ \\
\cline { 3 - 7 } & VI 15-s & $1 / 3$ & 0.50 & 0.15 & 6.0 & 19.6 \\
\multirow{3}{*}{ Rats - Bittar $(2010)^{2}$} & VI 30-s & $1 / 3$ & 0.43 & 0.15 & 6.0 & 45.6 \\
& VI 60-s & $1 / 3$ & 0.44 & 0.15 & 6.0 & $\infty$ \\
& VI 120-s & $1 / 3$ & 0.46 & 0.15 & 6.0 & $\infty$ \\
& VI 15-s & $1 / 3$ & 0.55 & 0.15 & 6.0 & 19.9 \\
MPR-machine & VI 30-s & $1 / 3$ & 0.57 & 0.15 & 6.0 & $\infty$ \\
& VI 60-s & $1 / 3$ & 0.43 & 0.15 & 6.0 & $\infty$ \\
& VI 120-s & $1 / 3$ & 0.42 & 0.15 & 6.0 & $\infty$ \\
\hline
\end{tabular}

Tabela 1. Estimativas dos parâmetros da Equação 2 quando aplicada a dados intrasessão de ratos (Bittar, 2010) e da máquina-MPR. O parâmetro $\delta$ é dado em segundos, enquanto os valores de $\mu$ são dados em minutos.

Três detalhes desse experimento são dignos de nota. Primeiramente, enquanto a distribuição de IRTs da máquina-MPR em VI 30-s atingiu o pico no segundo bin (.5 a $1 \mathrm{~s}$ ), a distribuição para os ratos atingiu o pico no terceiro bin (1 a $1.5 \mathrm{~s})$. Isso pode indicar que a duração média da resposta dos indivíduos reais foi ligeiramente maior que $.55 \mathrm{~s}$ (embora para um dos ratos a distribuição tenha atingindo o pico no segundo bin). Nenhum IRT foi observado no primeiro bin (0 a $.5 \mathrm{~s})$, porque os IRTs não podem ser menores que $\delta$.

Em segundo lugar, tanto a máquina-MPR como os ratos produziram um declínio na taxa de resposta sob altas taxas de reforço (Figura 4). Killeen (1994) interpreta tais desvios da hipérbole de Herrnstein como um efeito do truncamento da memória por respostas consumatórias, embora reduções na taxa de resposta em função da saciação e habituação também possam servir como uma explicação viável (McSweeney \& Hinson, 1992; ver Figura 3). A contribuição da saciação intra-sessão aos padrões de dados médios das sessões será discutida na próxima seção.

2. As estimativas de parâmetros apresentadas aqui diferem ligeiramente daquelas em Bittar et al. (2012), mesmo que os dados e o modelo sejam os mesmos. A razão para isso é que aqui nós ajustamos a Equação 2 no ponto médio dos bins, enquanto lá a equação foi ajustada nos limites superiores. 

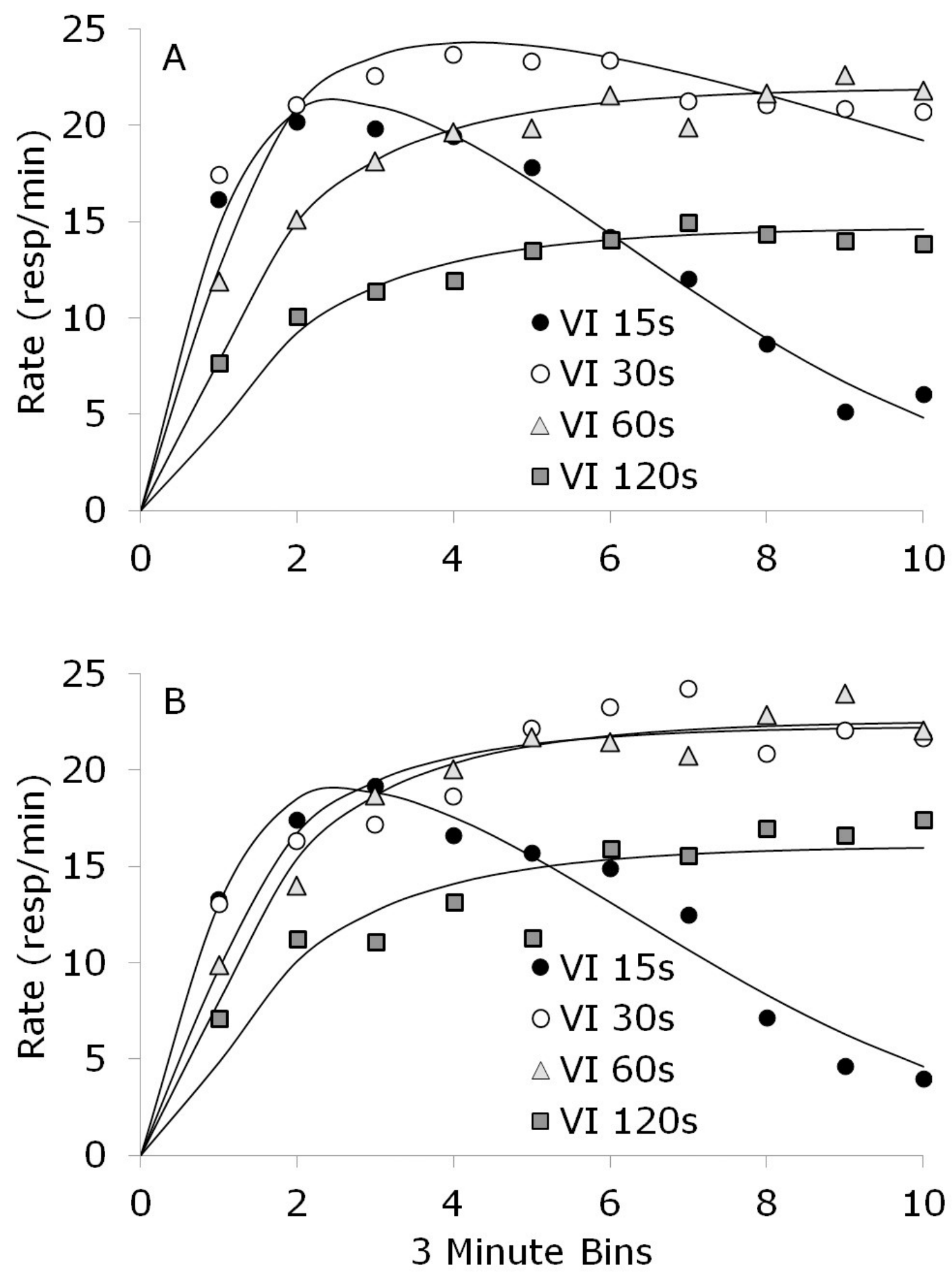

Figura 3. Responder intra-sessão sob vários esquemas VI, agregados sobre as últimas sessões em que cada condição esteve em efeito. O Painel A exibe dados de seis ratos (Bittar, 2010), enquanto o Painel B apresenta os dados gerados pela máquina-MPR. As curvas foram desenhadas pela Equação 2, juntamente com a Equação 6, com as estimativas de parâmetro dadas pela Tabela 1. As configurações da máquina são discutidas no texto. 


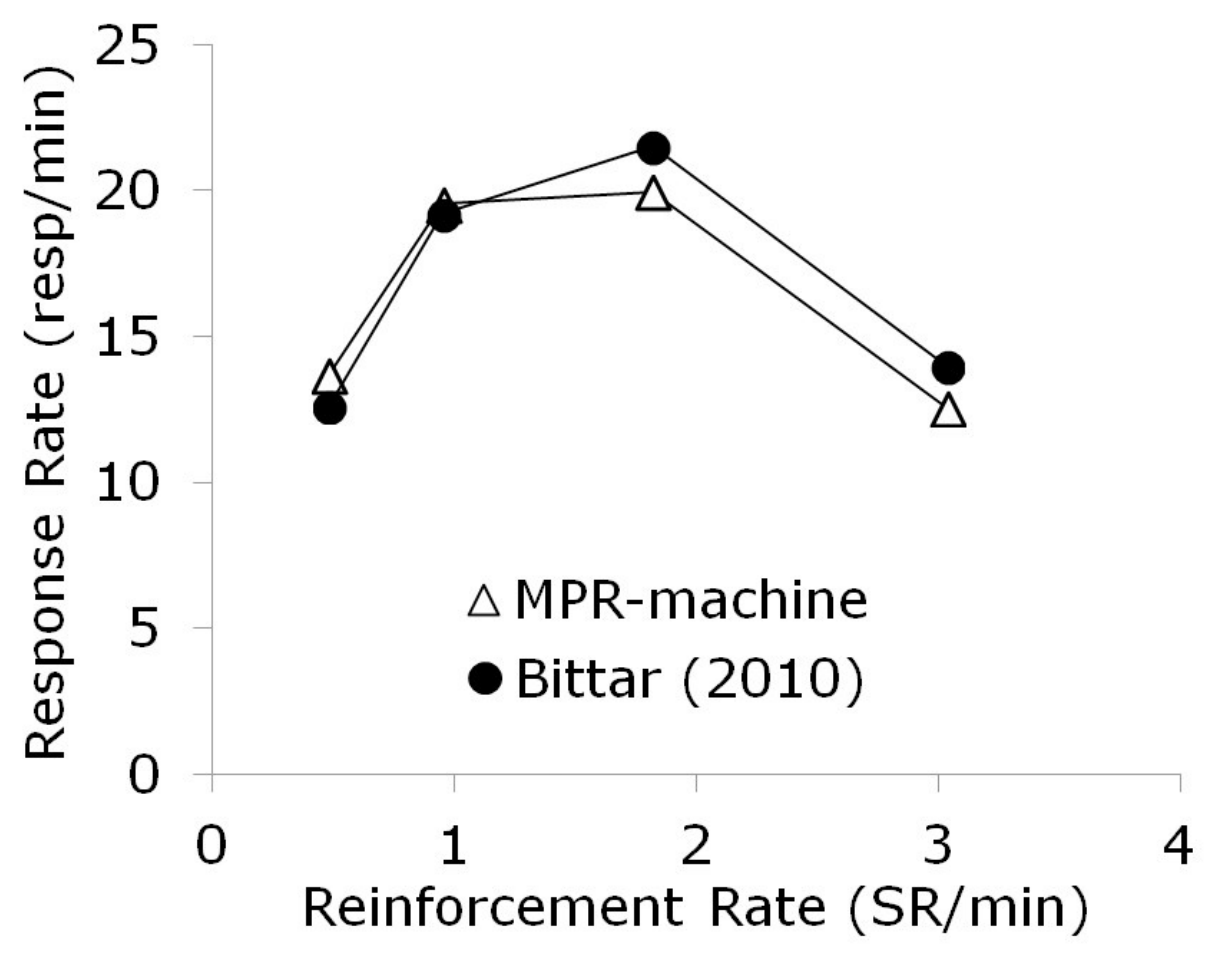

Figura 4. Taxa de resposta em função da taxa programada de reforçamento sob diferentes esquemas VI.

Em terceiro lugar, o valor médio de $C$ ao final das cinco últimas sessões em cada condição foi .36. Esse valor é extremamente próximo das estimativas de Killeen (1994) sobre a proporção de respostas-alvo nas trajetórias comportamentais sob esquemas VI. Como fixamos $C$ em 0.3 no início de cada condição, pode-se argumentar que esse parâmetro simplesmente se estabilizou ao redor de seu valor inicial. Para checar se foi este o caso, nós rodamos mais 100 sessões experimentais sob 8 diferentes esquemas VI (VI 5, 8, 15, 30, 50, 100,150 e 200-s), com cada condição começando com $C$ inicial $=1, A$ inicial $=.15, \xi=15$ e os demais parâmetros nos valores mencionados acima. $\mathrm{O}$ valor final obtido de $C$, agregado sobre as últimas 50 sessões de todas as condições, também foi 0.36 . O $C$ médio de cada condição está plotado em função da taxa de reforçamento na Figura 5. Essa figura torna claro que o valor estável de $C$ diminui enquanto a taxa de reforçamento aumenta, mas que 1/3 é, de fato, uma aproximação adequada para os esquemas VI tipicamente empregados na maior parte dos experimentos, pelo menos quando $\beta$ está dentro do intervalo tipicamente reportado na literatura. 


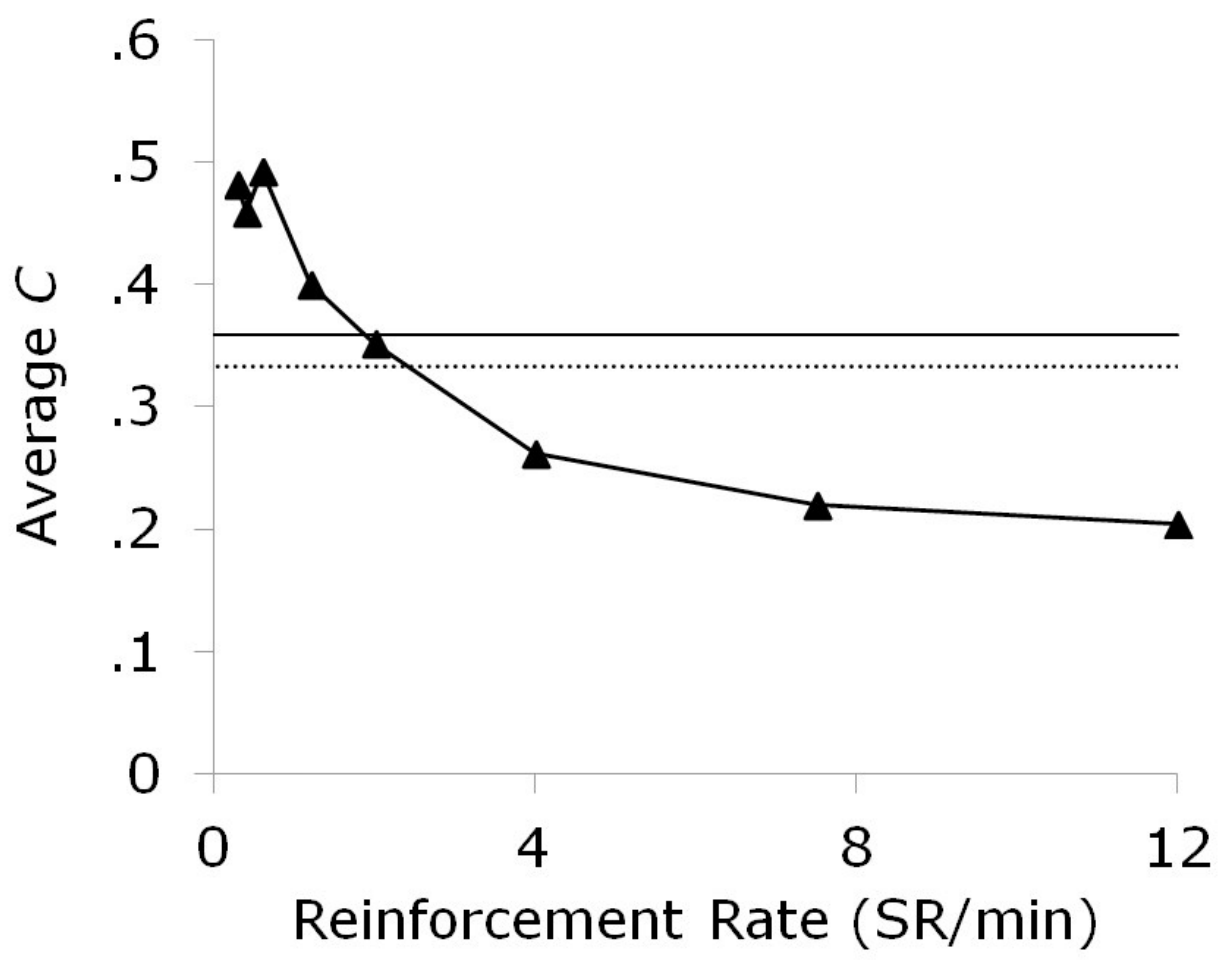

Figura 5. Valor final de $C$, agregado sobre as últimas 50 sessões em cada condição. A linha contínua horizontal representa a média dos pontos de dados (0.36), enquanto a linha pontilhada representa a estimativa de Killeen (1994) para $\rho$ sob esquemas VI (1/3).

\subsection{Experimento 2: Esquemas de razão fixa}

Neste experimento, nós executamos a máquina-MPR sob diferentes esquemas FR. Os parâmetros $Q, \mu, \beta, \delta$ e $\omega$ foram fixados nos mesmos valores do Experimento 1. O valor inicial de $A$ foi 0.15 e o valor inicial de $C$ foi sempre 1 . Sob diferentes condições, fixamos $\xi$ em $\infty, 20$ e 80 . Cada condição compreendeu 20 sessões; cada sessão durou 30 minutos.

Os resultados das últimas 5 sessões em cada condição estão plotados na Figura 6. Como esperado, a taxa de resposta aumentou até um pico e depois diminuiu linearmente até o break point. Esse padrão foi observado em todas as condições, e mimetiza perfeitamente dados de sujeitos reais respondendo sob esquemas FR (e.g., Bizo \& Killeen, 1997). 


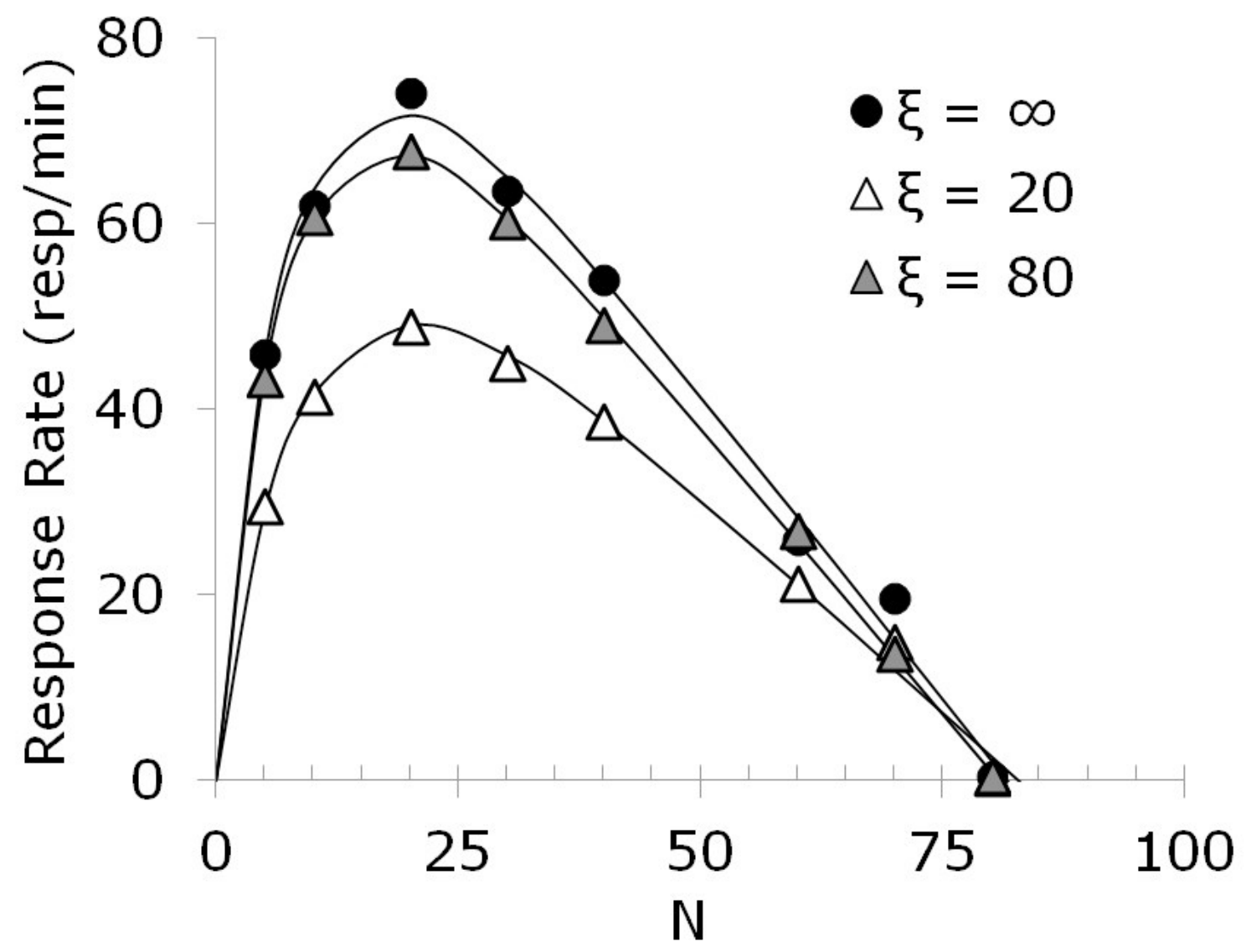

Figura 6. Taxa de resposta em função do critério de reforçamento $(N)$ sob diferentes esquemas FR. A taxa de saciação $(\xi)$ foi variada entre condições. As curvas foram desenhadas pela Equação 21, com as estimativas dos parâmetros dadas na Tabela 2.

\begin{tabular}{cccc} 
& \multicolumn{3}{c}{ Parameters } \\
\cline { 2 - 4 } Condition & $\mathrm{a}$ & $\beta$ & $\delta$ \\
\hline$\xi=20$ & 1.07 & 0.15 & 0.77 \\
$\xi=80$ & 0.81 & 0.18 & 0.60 \\
$\xi=\infty$ & 0.76 & 0.18 & 0.55 \\
\hline
\end{tabular}

Tabela 2. Estimativas dos parâmetros da Equação 21 quando aplicada aos dados simulados de FR pela máquina-MPR. O parâmetro $\delta$ é dado em segundos, enquanto $a$ é dado em minutos. 


\section{Discussão: Sobre as Limitações dos Modelos Finais da MPR}

Depois de construir e testar nosso mecanismo teórico, estamos em boa posição para levantar uma pergunta importante: as equações da MPR podem prever o comportamento da máquina-MPR? Essa questão pode parecer desnecessária. Se a máquina-MPR foi construída a partir das equações da MPR, então seu comportamento deveria certamente ser previsto pela teoria. No entanto, esse pode não ser o caso. Para entender o porquê, devemos considerar que a MPR contempla um conjunto de equações que podem ser divididas em três categorias: (1) os modelos básicos, que descrevem processos simples e independentes, (2) os modelos intermediários, que concatenam os modelos básicos em descrições integradas de processos complexos, e (3) os modelos finais, que concatenam modelos básicos e intermediários em equações únicas que preveem a taxa de resposta e conectam a MPR aos dados experimentais. Neste estudo, os modelos básicos estão representados pelas Equações 4 (uma descrição do acúmulo de excitação e saciação), 5 (uma descrição do decaimento da excitação) e 7 (uma descrição da atualização da memória). Esses são processos simples e independentes de memória e motivação. Os modelos intermediários, por outro lado, são exemplificados pela Equação 6 - uma concatenação das Equações 4 e 5 em um modelo integrado de como a excitação se acumula, perde seu suporte em virtude da saciação e depois se dissipa no curso de uma sessão experimental. Os modelos finais são representados pelas Equações 1 e 2 - as formas canônicas que concatenam modelos básicos e intermediários em uma descrição unificada da taxa de resposta sob diferentes esquemas de reforçamento.

Essa abordagem hierárquica à modelagem torna a MPR didática e geral. Ela é didática por torna explícita suas premissas centrais sobre os processos que subjazem o comportamento, bem como as maneiras precisas pelas quais esses processos interagem para produzir a taxa de resposta observada. E ela é geral porque permite que pesquisadores interessados possam

construir modelos derivados para necessidades específicas. A desvantagem é que a complexidade se acumula rapidamente quando saltamos de um passo da modelagem para o próximo. Essa complexidade crescente nos impõe alguns esforços de simplificação, e essas simplificações enfraquecem a acurácia do nosso modelo a cada novo nível de concatenação. 


\subsection{Aplicando a MPR a dados VI intra-sessão}

Uma boa ilustração de como a complexidade se acumula a cada passo de modelagem é dada pela Equação 6, nosso modelo da dinâmica da excitação. É uma formulação grande e complexa e, mesmo assim, é apenas a concatenação das Equações 4 e 5 - nada foi adicionado.

Como discutido antes, para prever taxas de resposta intra-sessão nós devemos substituir $R$ na Equação 6 pela função de feedback do esquema em operação e inserir a Equação 6 na Equação 2. Como a função de feedback torna $R$ dependente de $B$, o próximo passo seria resolver a equação resultante para $B$. Isso resulta em uma equação impraticavelmente complexa, de forma que apenas pudemos aplicar nosso modelo de excitação a taxas de resposta sob esquemas VI. Esses esquemas tornam $R$ relativamente constante em relação às variações em $B$, permitindo-nos deixar de lado as funções de feedback.

Essa simplificação, no entanto, nos coloca em uma posição desconfortável. Pequenas variações em $B$ ao longo de uma sessão nos asseguram que $R$ permaneça estável (como nossa simplificação requer), mas nos deixam com pouca informação para estimar a taxa de saciação $\xi$. Por outro lado, grandes variações em $B$ podem melhorar nossas estimativas de $\xi$, mas ao mesmo tempo ameaçam nossa equação simplificada, reduzindo nossa confiança no modelo. $\mathrm{O}$ resultado é que, mesmo que a Equação 6 capture corretamente a dinâmica da excitação, sua aplicação prática através da concatenação com a Equação 2 impõe sérias limitações à nossa capacidade de mensurar as variáveis que governam esse processo. Segue-se que nosso modelo do comportamento intra-sessão pode falhar em revelar os valores reais dos parâmetros subjacentes aos dados produzidos por uma implementação desse mesmo modelo.

Essa limitação é evidente quando tentamos estimar as configurações da máquina-MPR ajustando a Equação 6 juntamente com a Equação 2 aos dados simulados de VI da Figura 3B. Seguindo o mesmo procedimento usado para ajudar o modelo a dados de sujeitos reais (Bittar et al., 2012), nós fixamos $C$ em 1/3, deixando $\delta$ absorver quaisquer variações desse parâmetro. Nós também fixamos $\mu$ em 6 min e $Q$ em .15, deixando $\delta$ e $\xi$ livres para variar. As curvas na Figura 3B demonstram que o modelo se ajusta bem aos dados. Como podemos ver na Tabela 1, estimativas de $\delta$ se aproximam de .55 , a verdadeira configuração da máquina. Em esquemas mais pobres, $\delta$ assumiu valores menores para compensar os pequenos aumentos no valor real de $C$ (ver Figura 5). Por outro lado, estimativas de $\xi$ falharam em aproximar as verdadeiras configurações da máquina, especialmente em VI 30, 60 e 120-s. Isto ocorreu porque a curta 
duração da sessão (30 min) foi insuficiente para produzir uma saciação significativa sob esses esquemas, e nós não podemos medir a taxa de um processo que não teve tempo de se expressar. Em sessões mais longas, nós poderíamos ter visto uma redução expressiva no responder, mas isso não necessariamente melhoraria nossas estimativas de $\xi$, posto que, como discutimos, maiores variações no responder produzem variações significativas na taxa de reforçamento, enfraquecendo nossa premissa sobre a estabilidade de $R$. Isso é demonstrado neste estudo com VI 15-s, onde mesmo com a saciação se expressando por completo, $\xi$ foi estimado em 19.9 - o dobro de seu valor real.

\subsection{Aplicando a MPR a dados médios de sessões FR}

Como a média do responder na sessão é um agregado do que aconteceu ao longo de toda a sessão experimental, ela não está livre das complicações introduzidas por processos de warm-up e saciação. Na realidade, como McSweeney e Hinson (1992) demonstraram, nós podemos produzir grandes desvios da hipérbole de Herrnstein simplesmente estendendo a duração das sessões experimentais. Em sessões mais longas, a saciação se acumula o bastante para produzir decréscimos da taxa de resposta, especialmente sob taxas mais altas de reforçamento. Em sessões muito curtas (e.g., $5 \mathrm{~min}$ ), por outro lado, a relação entre taxa de resposta e de reforçamento se torna mais consistentemente hiperbólica.

A demonstração de que a saciação modula padrões de dados médios de sessão coloca um sério desafio a modelos matemáticos molares que não levam a saciação em conta - como é o caso da própria equação de Herrnstein (1970). É também um desafio para a MPR, já que os submodelos desenvolvidos para descrever a saciação (Killeen, 1995; Bittar et al., 2012) são aplicáveis apenas ao responder intra-sessão, e não aos dados médios das sessões. É óbvio que, em princípio, as mesmas equações que modelam mudanças intra-sessão na excitação, como a Equação 6, podem ser usadas para prever a excitação média ao longo de uma sessão. Na prática, porém, para obter essa média nós teríamos que integrar a Equação 6 sobre a duração da sessão e depois dividir essa excitação total pela duração da sessão. Como o leitor pode imaginar, integrar uma equação como esta não é simples. Mesmo se pudéssemos resolver esse desafio matemático, ainda seríamos deixados com o problema de inserir a fórmula obtida na Equação 1 ou 2 e resolvê-las para $B$. 
Ao ajustar a Equação 1 a dados médios de sessão, Killeen (1994) ignorou essas complicações assumindo simplesmente que

$$
A=a R
$$

onde $a$ são os segundos de excitação eliciados por cada reforçador. Já que, como assumimos, um reforçador provê um impulso de excitação $Q$, o parâmetro $a$ é a integral da função descrevendo o decaimento exponencial de $Q$, de modo que $a=Q \mu$, onde $\mu$ é a constante temporal do decaimento. Se a saciação é um decréscimo no valor de $Q$ a cada nova apresentação do reforçador, o efeito global da saciação ao longo de uma sessão será reduzir o valor médio de $a$.

Para testar a adequação dessas formulações, nós ajustamos a Equação 1 aos dados FR exibidos na Figura 6. Para isso, substituímos $A$ por $a R$ e a taxa de reforçamento $R$ por $B / N$. Resolvendo para $B$, obtemos

$$
B=\frac{C}{\delta}-\frac{N}{a} .
$$

Sob esquemas FR, Killeen (1994) assume que $C=1-(1-\beta)^{N-1}$. Esta equação, no entanto, é baseada no modelo pré-assintótico do comportamento que abandonamos anteriormente. Para construir nossa máquina, nós adotamos uma abordagem estocástica de $C$, deixando esse parâmetro representar a proporção dos efeitos do reforçador que fazem contato com a resposta-alvo na memória e, ao mesmo tempo, a probabilidade de observarmos uma resposta-alvo em cada ponto da trajetória no próximo trial. Esse papel duplo introduz uma dinâmica em $C$ que, a cada trial, se aproxima de um ponto de equilíbrio. Demonstramos no Apêndice que sob esquemas FR esse ponto pode ser aproximado por

$$
C=1-(1-\beta) e^{(1-N) \beta^{1.23}}
$$

A Figura 6 mostra que as Equações 21 e 22 oferecem um bom ajuste aos dados simulados. No entanto, a Tabela 2 nos mostra que a capacidade da equação de revelar as configurações da máquina decresce sob altas taxas de saciação (representada por valores menores de $\xi)$.

Para entender porque isso ocorre, começaremos analisando a condição de não-saciação $(\xi=\infty)$. Essa condição oferece um campo de teste confortável para a Equação 21, já que a 
própria equação ignora processos de saciação. Em consequência, o modelo foi capaz de estimar as configurações exatas da máquina para $\beta$ e $\delta$. Como $a=Q \mu$, o valor real de $a$ nesta simulação foi $0.9 \mathrm{~min}$ - um pouco mais do que o valor estimado.

Porque a Equação 20 subestimou o valor de $a$ ? Porque, apesar de eliminar a saciação (deixando $\xi=\infty$ ), nós não eliminamos o warm-up. No decorrer de uma sessão, a excitação eliciada por reforçadores se acumula de acordo com a equação abaixo (Killeen et al., 1978):

$$
\bar{A}_{t}=a R\left(1-e^{\frac{-t}{\mu}}\right)
$$

Se nenhuma saciação ocorre (i.e., $a$ permanece constante), enquanto o tempo dentro da sessão tende ao infinito a excitação do organismo se aproxima de uma assíntota dada por

$$
\lim _{t \rightarrow \infty} \bar{A}_{t}=a R
$$

A Equação 24 é, como o leitor reconhece, idêntica à Equação 20 - o modelo simplificado de excitação usado quando a MPR é aplicada a dados agregados de sessão. Isso porque, ao construir seu modelo canônico, além de ignorar a saciação, Killeen (1994) também desconsiderou o warm-up, assumindo simplificadamente que o organismo inicia e conclui a sessão com o nível de excitação na assíntota.

Embora, como discutimos, seja difícil enriquecer a Equação 21 com um modelo de saciação, nós podemos facilmente equipá-la com uma correção para warm-up. Para fazer essa correção, obtemos a excitação média da sessão $\left(\bar{A}_{S}\right)$ dividindo a integral da Equação 23 pela duração da sessão $(T)$ :

$$
\bar{A}_{S}=\frac{a R\left[T+\left(e^{-\frac{T}{\mu}}-1\right) \mu\right]}{T} .
$$

Dessa forma, a excitação média da sessão representa apenas uma proporção $P$ da assíntota, dada por

$$
P=\frac{\bar{A}_{S}}{a R}=\frac{T+\left(e^{-\frac{T}{\mu}}-1\right) \mu}{T}
$$


Para corrigir a Equação 21 para warm-up, devemos simplesmente estabelecer $a=a^{\prime} P$, onde $a^{\prime}=Q \mu$. Na condição de não-saciação do Experimento 2, nós usamos uma sessão de 30 minutos, e fixamos $\mu$ em $6 \mathrm{~min}$, o que resulta em $P=0.8$ e $a=0.72 \mathrm{~min}$. Isso é menos do que o Estimado pela Equação 21, porque na Equação $23 \bar{A}_{0}=0$, enquanto no Experimento 2 nós fixamos a excitação inicial da máquina em 0.15 . Integrando a excitação inicial sobre seu decaimento, dividindo o resultado por $T$ e somando com 0.72 resulta em 0.75 $\min$ - um valor extremamente próximo do estimado (0.76 $\mathrm{min})$.

A conclusão é que, quando nenhuma saciação ocorre, a Equação 21 fornece uma forma muito precisa de medir os parâmetros que governam nossa máquina e - na extensão em que seu funcionamento é bem modelado pela máquina - os nossos sujeitos reais.

A precisão da Equação 21 se mantém quando $\xi=80$, onde nós observamos apenas uma pequena perda na precisão na qual os parâmetros são estimados. No entanto, quando a saciação progride mais rapidamente $(\xi=20)$, vemos que a Equação 21 se confunde. Como a saciação se manifesta mais marcadamente em esquemas ricos do que pobres, ela deprime a taxa de resposta em razões pequenas, mas tem pouco efeito em razões maiores. O resultado é uma redução na inclinação da curva após o pico, que é acomodada pela Equação 21 inflando os valores estimados de $a$ e $\delta$ enquanto o valor estimado de $\beta$ é reduzido (ver Tabela 2).

Esse aumento em $a$ quando a saciação é maior é inesperado. Como a saciação reduz o valor do reforçador ao longo de uma sessão, seria esperado que seu efeito fosse reduzir $a$, e não o oposto. Mesmo assim, como a saciação mais rápida tende a ocorrer com reforçadores maiores, um pesquisador aplicando a Equação 21 aos seus dados poderia prontamente atribuir o aumento em $a$ a um aumento no tamanho do reforçador, concluindo que reforçadores maiores eliciam mais excitação. Mesmo que isso seja verdadeiro (e algumas evidências apontam nesse sentido; veja Bittar et al., 2012), essa conclusão no caso do Experimento 2 pode ser enganosa. Nós sabemos os valores reais de cada parâmetro por trás dos dados na Figura 6, e sabemos que $Q \mu$ permaneceu invariante ao longo das condições. O valor estimado de $a$ não aumentou porque os reforçadores em uma condição eliciaram mais excitação, mas porque a Equação 21 falhou em acomodar apropriadamente os efeitos da saciação.

O mesmo vale para $\delta$. Como a Tabela 2 demonstra, saciação mais rápida tende a resultar em estimativas infladas desse parâmetro. Isso pode explicar porque efeitos de 
operações motivacionais são frequentemente interpretados pela MPR como efeitos motores. Em seu artigo seminal da MPR, Killeen (1994) escreveu:

“Observe o papel importante de $\delta$ [...]. Muitos dos efeitos de operações que tem sido tradicionalmente interpretados como motivacionais podem, na realidade, afetar a motivação apenas indiretamente pela modificação da duração mínima da resposta.” (p. 115)

Outra possibilidade é que $\delta$ está sendo forçado a absorver os efeitos motivacionais de processos que foram supersimplificados nas Equações 1 e 21. 


\section{CAPÍTULO 3}

Adicionando Mais Engrenagens 


\section{Estendendo a MPR}

Até agora, a máquina-MPR serviu a três propósitos. Primeiramente, ela construiu uma ponte entre a MPR e os modelos estocásticos do comportamento. Em segundo lugar, ela auxiliou a compreensão da MPR ao permitir uma visualização integrada e organizada de cada um de seus processos hipotéticos. Em terceiro lugar, ela nos ajudou a compreender as limitações dos modelos finais da MPR, e como as simplificações podem gerar desvios nas estimativas dos parâmetros. Essas contribuições fazem da máquina um recurso didático e uma ferramenta de validação, mas pouco realizam para estender o poder e generalidade da MPR.

Neste capítulo, iremos demonstrar que, ao produzir comportamento simulado diretamente a partir dos modelos básicos da MPR, a máquina-MPR nos liberta das restrições dos modelos finais, permitindo-nos observar o trabalho da teoria em tempo real, enquanto ela simula fenômenos comportamentais além do alcance para o qual a MPR foi originalmente desenvolvida. Especificamente, verificaremos se nossa máquina é capaz de simular dois fenômenos bem conhecidos que ocorrem sob esquemas múltiplos: (1) o contraste comportamental e (2) a desaceleração da extinção em um componente quando o componente alternativo ainda está entregando reforçadores. No entanto, antes de executar nossos experimentos, devemos equipar a máquina com algumas engrenagens adicionais. Primeiramente, devemos dotá-la com responder discriminativo. Em segundo lugar, precisamos de uma forma de simular o desacoplamento. Por fim, devemos fornecer o modelo de recuperação da saciação que foi sugerido acima ao simularmos o responder em VI.

\subsection{Controle de estímulos}

Nos esquemas múltiplos, dois ou mais estímulos discriminativos se alternam ao longo da sessão, com cada um deles sinalizando quando um esquema simples específico está em operação. Com o treino, os sujeitos aprendem a responder diferencialmente aos estímulos discriminativos, modulando seu responder de acordo com o estímulo correntemente apresentado. Como pode a MPR explicar esse tipo de aprendizagem?

Embora a teoria original (Killeen, 1994) não diga nada sobre controle de estímulos, podemos encontrar espaço para processos discriminativos na MPR ao inspecionar os parâmetros fundamentais da Equação 1. Por exemplo, mesmo que um treinamento específico possa colocar a duração da resposta sob controle discriminativo, é improvável que um 
esquema múltiplo típico, insensível a $\delta$, produza taxas de resposta diferenciais por influência desse parâmetro. O parâmetro de excitação $A$, por outro lado, pode ser um bom candidato. Os estímulos discriminativos podem adquirir funções excitatórias através de condicionamento respondente, e os estímulos associados a taxas mais altas de reforçamento podem eliciar mais excitação que os estímulos associados com esquemas mais pobres. Tal excitação condicionada pode ajudar a explicar porque mesmo reforçamento não contingente aumenta a resistência à extinção na presença de um estímulo discriminativo (Nevin et al., 1990).

Embora a excitação condicionada possa ser importante para explicar a performance sob esquemas múltiplos, parece que o link mais óbvio para o controle de estímulos na Equação 1 é dado pelo coeficiente de acoplamento $C$. Como vimos, esse parâmetro sumariza os efeitos da história de treino, e simboliza as representações do organismo acerca das contingências de reforçamento em operação.

De acordo com isso, nas simulações abaixo nós dotaremos nossa máquina-MPR com responder discriminativo equipando-a com um coeficiente de acoplamento para cada estímulo em um esquema múltiplo. Se um reforçador é apresentado quando o estímulo $X$ está em operação, o coeficiente $C_{X}$ é atualizado de acordo com o conteúdo da memória nesse momento exato, como postulado pela Equação 14. Se um reforçador é apresentado sob o estímulo $Y$, então é $C_{Y}$ que é atualizado. Seguindo o mesmo raciocínio, o coeficiente $C_{X}$ determina a probabilidade de uma resposta ser uma resposta-alvo quando o estímulo $X$ está presente, e o mesmo se aplica ao coeficiente $C_{Y}$. Com isso, a arquitetura da nossa máquina permanece fundamentalmente inalterada. A única modificação é que o $C$ ativo na Figura 1 depende do estímulo discriminativo corrente.

É importante notar que, embora essa extensão quebre o coeficiente de acoplamento em dois (ou mais), a memória $M$ permanece única. Dessa forma, ao menos que um reforçador apague a memória ao final de um dos componentes do esquema múltiplo, a máquina entra no próximo componente com sua memória já populada em algum grau. Embora a adequação teórica desse detalhe possa ser discutida, notamos que a decisão de resetar ou não a memória no início de cada componente tem efeitos insignificantes sobre as taxas de resposta obtidas. 


\subsection{Desacoplamento}

Enquanto um animal se comporta, sua memória de curto prazo $(M)$ vai se preenchendo com traços de cada resposta da trajetória. Quando um reforçador é obtido, ele também adentra a memória de curto prazo, apagando-a e criando um traço na memória de longo prazo da trajetória que acabou de ser reforçada $(C)$. Na próxima oportunidade, o sujeito irá preencher novamente sua memória com o mesmo mix de respostas que representou como tendo sido efetivo no passado. (Essa é a razão pela qual nossa máquina-MPR re-popula sua memória $M$ em cada trial com as proporções de respostas ditadas por $C$, que, por sua vez, é determinado por um rastreamento constante do último $M$ reforçado.)

Mas o que acontece quando um mix de respostas recordado consistentemente falha em predizer a produção de um reforçador, como quando as condições são alteradas para um esquema de extinção? Nós podemos supor que o traço de longo prazo sobre as contingências passadas esvanece cada vez que uma falha em produzir um reforçador é percebida pelo sujeito. Como é geralmente mais fácil reinstaurar uma classe operante extinta do que estabelecê-la em primeiro lugar (Podlesnik \& Shahan, 2009), também podemos assumir que embora o traço de longo prazo se torne menos ativo, ele não é completamente extinto.

Um modelo para esse fenômeno guardaria grande semelhança com os modelos de memória procedural da teoria ACT-R (Anderson et al., 2004). Nessa arquitetura cognitiva, o sujeito é sempre confrontado com um padrão de informações, de fontes externas e internas. Informações externas compreendem os estímulos ambientais, enquanto as informações internas compreendem os traços ativos da memória declarativa e o conhecimento sobre os objetivos atuais. A função da memória procedural é selecionar a regra de produção (i.e., o output comportamental) mais apropriado ao contexto. O problema é que a qualquer tempo existem múltiplas regras de produção competindo por expressão, de modo que o sistema deve escolher qual expressar baseado em suas utilidades respectivas. A utilidade de uma regra de produção é fortemente determinada pela probabilidade de sua emissão resultar na consecução do objetivo atual. Essa probabilidade $(p)$ é dada por

$$
p=\frac{S}{S+F}
$$

onde $S$ é o número de vezes que a regra de produção foi bem-sucedida no passado, enquanto $F$ é a contagem de fracassos prévios. 
Para modelar o desacoplamento, nós poderíamos equipar nossa máquina com a habilidade de detectar o sucesso ou fracasso de uma trajetória em produzir um reforçador, e usar uma equação como a Equação 27 para ponderar o $C$. À medida que o número de fracassos se acumula, $p$ tende a 0 , carregando consigo a probabilidade de uma resposta-alvo. Esse modelo simples poderia explicar facilmente o efeito de extinção sob reforçamento parcial, já que altas taxas de reforçamento resultariam em trajetórias menores e, consequentemente, em altas taxas de detecção de fracassos uma vez que o esquema fosse alterado para extinção. Sob esquemas mais pobres, a contagem de fracassos se acumularia mais lentamente, dando ao comportamento maior persistência.

Como o desenvolvimento de tal modelo completo de desacoplamento está além do escopo do presente estudo, nos próximos experimentos nós iremos simular superficialmente esse fenômeno deixando o parâmetro $C$ associado ao componente de extinção de um esquema múltiplo cair para $\alpha C$ após cada sessão de extinção. O peso $\alpha$ pode ser qualquer valor entre 0 e 1; em todos os experimentos abaixo, ele foi fixado em .8.

\subsection{Privação}

Ao simular o responder em VI no Experimento 1, nós atribuímos valores maiores para a taxa de saciação $\xi$ nas condições com esquemas mais pobres. Como valores maiores de $\xi$ implicam saciação mais lenta, fizemos isso para implementar a ideia de que sob baixas taxas de reforçamento a saciação promovida por cada reforçador pode se dissipar entre apresentações sucessivas. Os experimentos abaixo requerem uma abordagem mais precisa desse processo. Em outras palavras, precisamos de um modelo de privação.

No modelo de dinâmica da excitação implementado na máquina-MPR, a saciação avança por incrementos na variável $n$ cada vez que um reforçador é consumido. Essa variável, portanto, pode ser compreendida como um índice de repleção. Coerentemente, nós podemos modelar a privação como depleção, movendo a variável $n$ na direção oposta à medida que se passa o tempo desde o último reforçador. A equação a seguir faz precisamente isso:

$$
n_{t}=n_{0} e^{\frac{-t}{\gamma}}
$$


onde $n_{0}$ é a repleção no momento do último reforçador, e $t$ é o tempo desde o último reforçador. O parâmetro $\gamma$ é a constante temporal da depleção, representando o tempo $t$ no qual $63.2 \%$ da repleção inicial $\left(n_{0}\right)$ já foi perdida. Valores maiores para $\gamma$ implicam uma taxa de depleção mais lenta - nos experimentos abaixo, ele foi fixado em 12 h. É importante notar que, de acordo com a Equação 4, enquanto $n$ é restaurado a 0 em virtude da privação, o reforçador recupera sua capacidade de eliciar excitação.

Agora que a máquina-MPR está dotada de responder discriminado, desacoplamento e privação, estamos prontos para simular alguns fenômenos de esquemas múltiplos.

\section{Experimento 3: Contraste Comportamental}

O comportamento sob esquemas múltiplos de reforçamento pode ser complexo. Apesar da clara separação feita pelo experimentador entre os esquemas componentes, existe um organismo único atravessando cada alternância de componentes dentro da sessão. Com isso, interações entre os esquemas componentes podem emergir, e as condições de reforçamento em um componente frequentemente influenciam o responder no outro.

Uma das interações mais importantes entre os componentes de um esquema múltiplo é o chamado contraste comportamental (Reynolds, 1961a; Williams, 1983). Esse fenômeno é tipicamente estudado treinando-se o sujeito a responder sob mult VI $x$ VI $x$ (condição de linha de base). Uma vez que o responder está estabelecido, o esquema é alterado para mult VI $x$ VI $y$ (condição de contraste). Se o componente VI $y$ é mais pobre do que o VI $x$, a taxa de resposta em VI $x$ pode aumentar, independentemente do fato de que este componente permaneceu inalterado ao longo das condições. Isso é o contraste positivo. Por outro lado, se o componente VI $y$ é mais rico do que o VI $x$, a taxa de resposta em VI $x$ pode cair - um fenômeno conhecido como contraste negativo. Deste ponto em diante, o componente que se mantém inalterado ao longo das condições será chamado de componente constante, enquanto o outro será chamado de componente variável.

Embora o contraste comportamental possa ser interpretado como evidência da relatividade do reforçamento (Herrnstein, 1970), uma abordagem mais rigorosamente mecânica também pode ser sugerida. No caso da máquina-MPR, por exemplo, um esquema mais pobre associado com o componente variável poderia permitir alguma recuperação da 
saciação, preservando a capacidade dos reforçadores de eliciar e sustentar a excitação no componente constante. Um esquema mais rico, por outro lado, poderia acelerar a saciação, reduzindo a excitação geral e reduzindo a taxa de resposta no componente constante.

Para testar a capacidade da máquina-MPR de simular contraste, nós a executamos sob mult VI 20-s VI 20-s por 10 sessões. Depois, nós mudamos o esquema para mult VI 20-s EXT nas próximas 10 sessões. Finalmente, nós retornamos o esquema para mult VI 20-s VI 20-s por mais dez sessões adicionais. Os valores dos parâmetros $Q, \mu, \beta$ e $\omega$ foram os mesmos dos experimentos anteriores. Fixamos $\delta=.3$ e $\xi=10$. A excitação inicial, bem como o acoplamento inicial para cada componente, foi definida em .5. Como antes, cada sessão começou com o valor final de $C$ da sessão anterior. $O$ desacoplamento na extinção foi simulado da maneira descrita acima. Cada sessão durou $60 \mathrm{~min}$, com componentes se alternando a cada 2 min. Os resultados estão apresentados na Figura 7, exibidos como taxas de resposta médias em cada componente ao longo das 30 sessões.

Como podemos ver, a máquina-MPR foi capaz de fornecer uma simulação realista do contraste positivo. Para entender porque esse contraste ocorreu, podemos ver a Figura 8, que exibe a dinâmica da excitação em uma sessão de linha de base e uma de contraste. Durante a sessão de linha de base, a apresentação regular dos reforçadores levou a excitação a um pico. Ao mesmo tempo, a saciação crescente reduziu o impulso de excitação engendrado por cada reforçador, até um ponto no qual a excitação começou a decair exponencialmente de acordo com a Equação 5. Durante a sessão de contraste, por outro lado, o esquema de extinção (indicado pelas barras cinzas) forneceu um período de descanso no qual a máquina se recuperou da saciação da forma descrita pela Equação 28. Esta recuperação preveniu o decaimento intra-sessão da excitação, produzindo as altas taxas de excitação observadas no componente constante. 


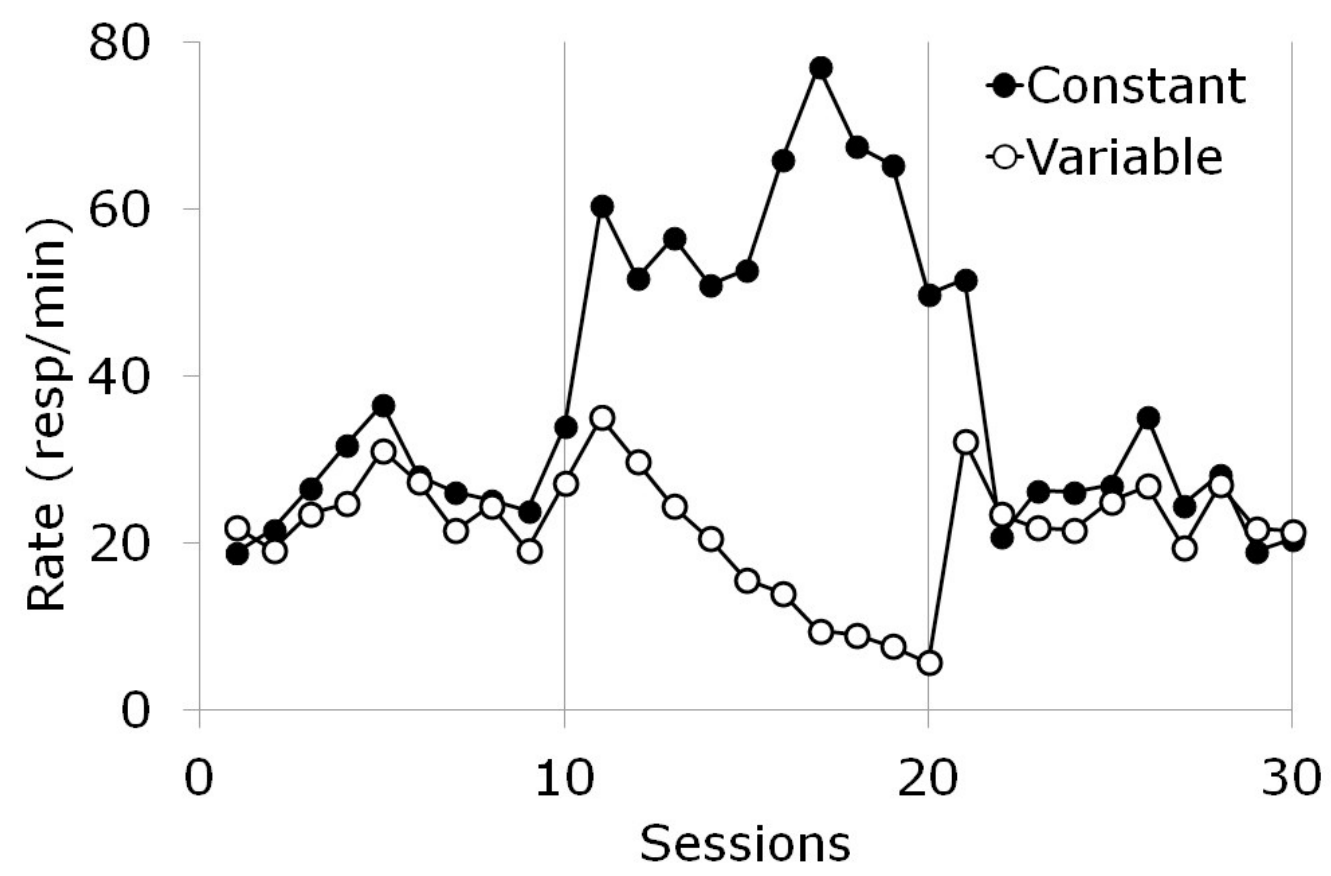

Figura 7. Taxas de resposta da máquina-MPR sob um esquema múltiplo de reforçamento. Das sessões 0 a 10, ambos os componentes entregavam reforçadores em VI 20 s. Das sessões 11 a 20, um componente ("variável") foi alterado para extinção, enquanto o outro ("constante") permaneceu em VI 20-s. Das sessões 21 a 30, ambos os componentes voltaram para VI 20 -s.

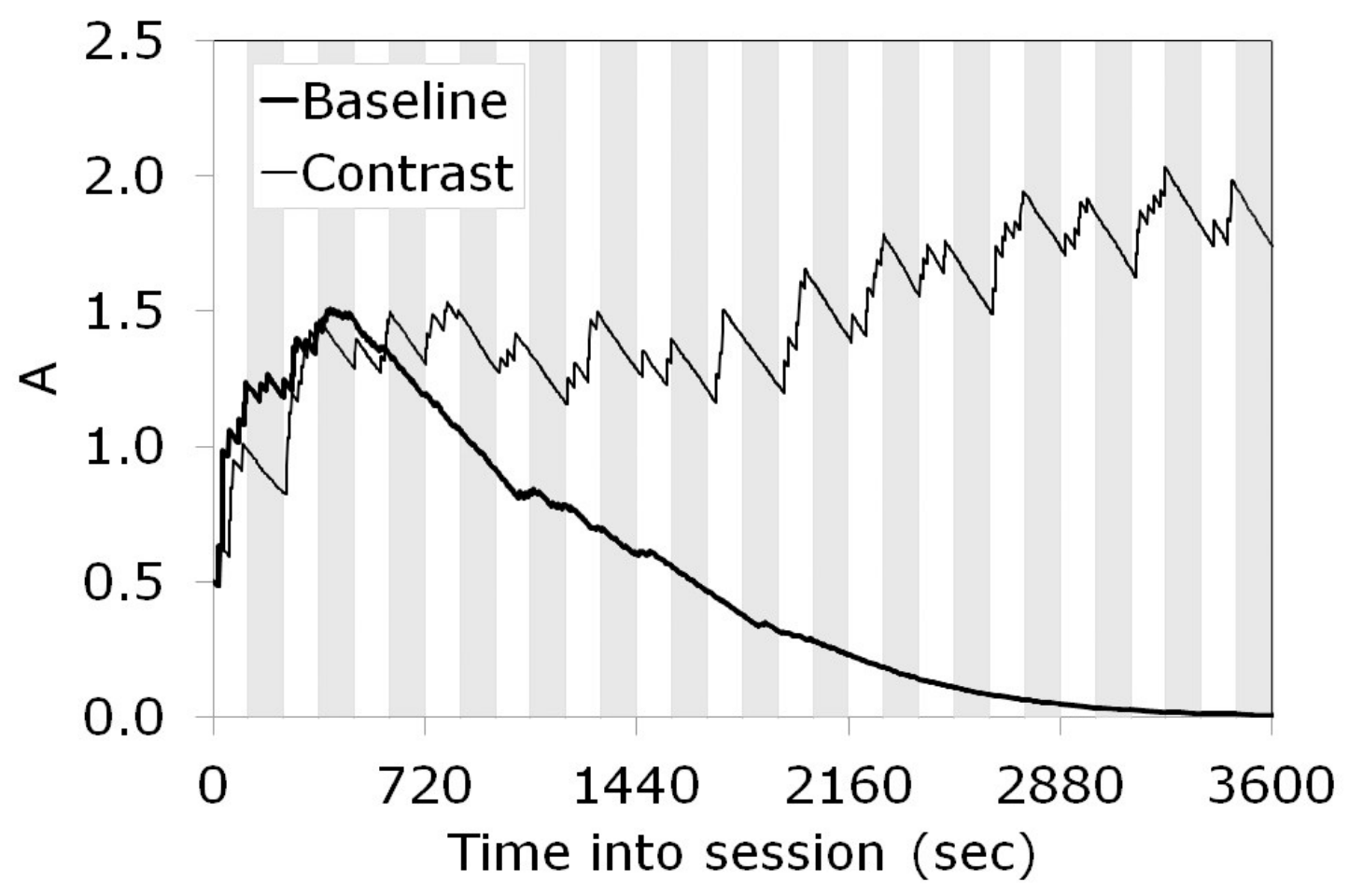

Figura 8. Dinâmica intra-sessão da excitação em uma sessão de linha de base (mult VI 20-s VI 20-s) e uma de contraste (mult VI 20-s EXT). O segundo componente (que foi alterado para EXT durante a sessão de contraste) está representado pelas barras cinzas. 


\section{Experimento 4: Contraste e Responder Intra-Sessão}

A ideia de que processos simples de saciação e privação podem explicar interações entre os componentes de um esquema múltiplo lembra a teoria de McSweeney e Weatherly (1998) sobre o contraste comportamental. Eles argumentaram que o contraste pode ser explicado por duas premissas simples: (1) um processo similar à habituação ocorre com um reforçador sempre que ele é apresentado e (2) esse processo reduz a habilidade do reforçador de suportar responder operante. Segue-se que um esquema mais pobre associado com o componente variável pode reduzir a quantidade total de habituação, preservando o responder no componente constante. Um esquema mais rico, por outro lado, pode aumentar a quantidade total de habituação, desvalorizando o reforçador e deprimindo o responder. A semelhança dessa teoria com nossa abordagem em termos de saciação e privação parece ainda mais próxima se lembrarmos que a habituação pode ser considerada um dos componentes da saciação (Swithers \& Hall, 1994). A diferença central é que nosso modelo é mais direto sobre como os reforçadores sustentam o responder: os reforçadores sustentam o responder ao eliciar excitação.

Independentemente dessa e de outras diferenças, ambas as teorias preveem que o responder no componente constante sofre menos redução intra-sessão durante o contraste positivo do que na condição de linha de base; por outro lado, o responder no componente constante sofre uma redução intra-sessão mais pronunciada durante o contraste negativo do que durante a linha de base.

McSweeney et al. (2004) testou sua previsão treinando oito pombos para responder sob mult VI 30-s VI 30-s. Eles depois moveram metade dos sujeitos dessa condição de linha de base para uma condição de contraste positivo, onde um esquema mult VI 30-s EXT estava em efeito. Os pombos restantes foram movidos para uma condição de contraste negativo na qual eles responderam por reforçadores sob mult VI 30-s VI 7.5-s. Finalmente, todos os sujeitos foram retornados para a condição de linha de base. Cada condição compreendeu 30 sessões, e cada condição durou 60 min. Os componentes tinham $30 \mathrm{~s}$ de duração.

Os Painéis B e D da Figura 9 exibem os resultados do experimento. Como podemos ver, a predição foi correta: o contraste positivo se expressou no nível intra-sessão como uma prevenção da redução do responder no componente constante, enquanto o contraste negativo se expressou como uma acentuação marcante dessa redução. 

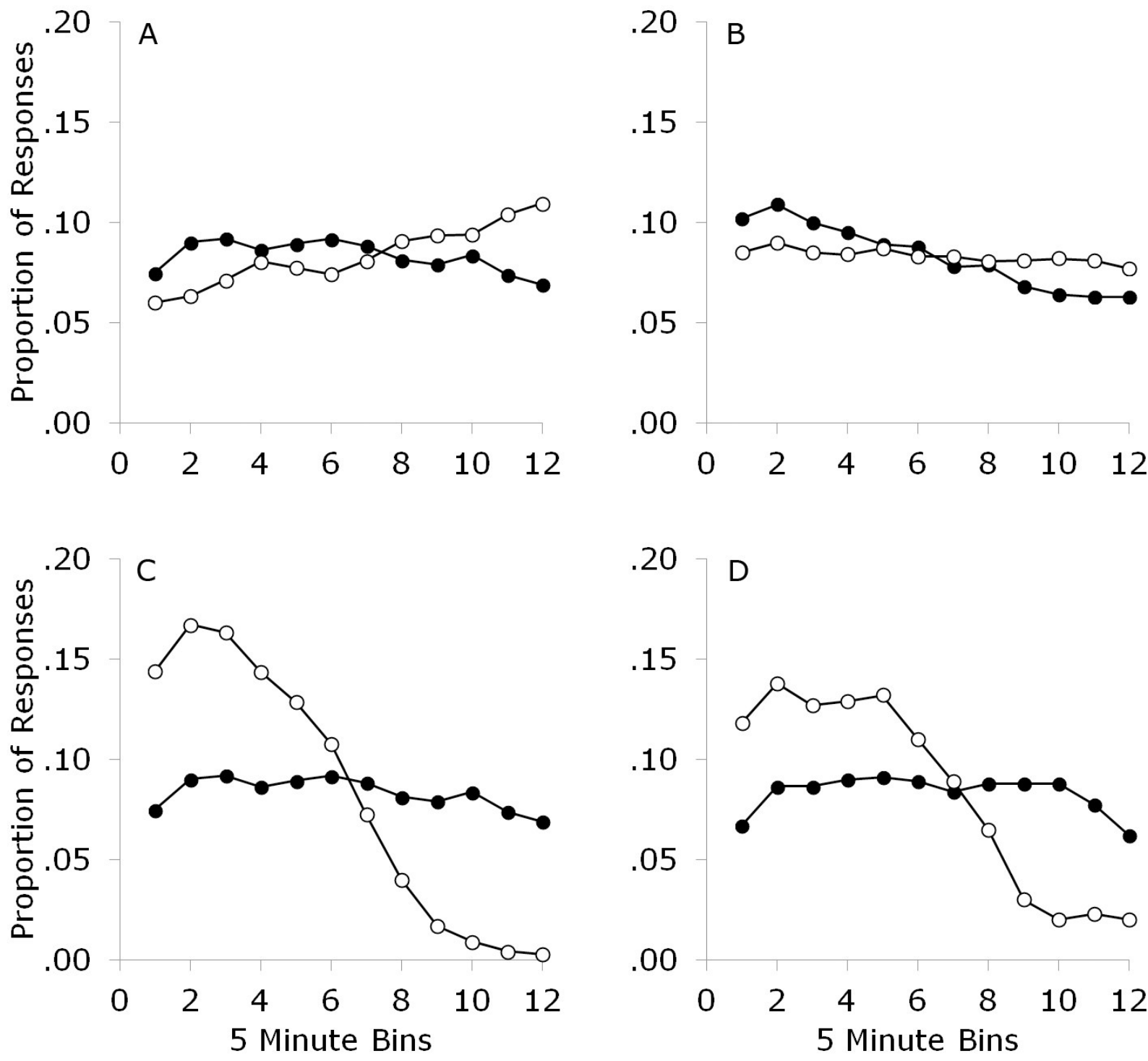

Figura 9. Padrões intra-sessão do responder no componente constante nas condições de linha de base (círculos preenchidos) e de contraste (círculos abertos). Os painéis de cima mostram os resultados para contraste positivo, e os de baixo para contraste negativo. A coluna da direita mostra dados de pombos reais (McSweeney et al., 2004), enquanto a da esquerda foi gerada pela máquina-MPR em um procedimento idêntico.

Usando as configurações do Experimento 3, nós sujeitamos a máquina-MPR aos exatos mesmos procedimentos descritos por McSweeney et al. (2004). Os dados gerados pela máquina, plotados nos Painéis $\mathrm{A}$ e $\mathrm{C}$ da Figura 9, mimetizam acuradamente os dados reais de pombos. Logo, além de oferecer uma simulação realista do contraste no nível agregado de sessão (Experimento 3), a máquina-MPR o fez através dos mesmos mecanismos encontrados quando o contraste é estudado no nível intra-sessão. 


\section{Experimento 5: Extinção sob Esquemas Múltiplos}

Outra importante interação encontrada em esquemas múltiplos diz respeito à desaceleração da extinção em um componente quando um segundo componente ainda está entregando reforçadores (Reynolds, 1961b). Após prover um exame experimental desse fenômeno, Reynolds (1968) concluiu que "diferenças na velocidade de extinção em um componente de um esquema múltiplo são criadas por vários níveis de facilitação do responder pelas condições prevalentes no outro componente [...]".

De acordo com nossas considerações prévias, o desacoplamento no componente associado com a extinção procederá na mesma velocidade independentemente das condições de reforçamento no segundo componente. No entanto, como o responder é conjuntamente determinado pelo acoplamento e pela excitação, e como a excitação geral é mais alta quando o segundo componente está entregando reforçadores, nosso modelo prevê uma desaceleração da extinção por reforçamento alternativo mesmo que a velocidade de desacoplamento não seja afetada pelo que ocorre no segundo componente. Logo, concordamos com a observação de Reynolds (1968), e acrescentamos que a "facilitação do responder" que ele apontou é promovida pela excitação.

No presente experimento, testamos se a máquina-MPR é capaz de simular a extinção sob esquemas múltiplos de reforçamento. Em uma condição, a máquina foi testada sob 10 sessões de mult VI 20-s VI 20-s (fase de treino), e depois movida para mult VI 20-s EXT por mais 8 sessões (fase de extinção). Na outra condição, o esquema em operação durante a fase de extinção foi mult EXT EXT, com todo o resto se mantendo igual. As configurações da máquina foram as mesmas dos Experimentos 3 e 4. Como podemos ver na Figura 10, o modelo foi capaz de simular a desaceleração da extinção pelo reforçamento alternativo. 


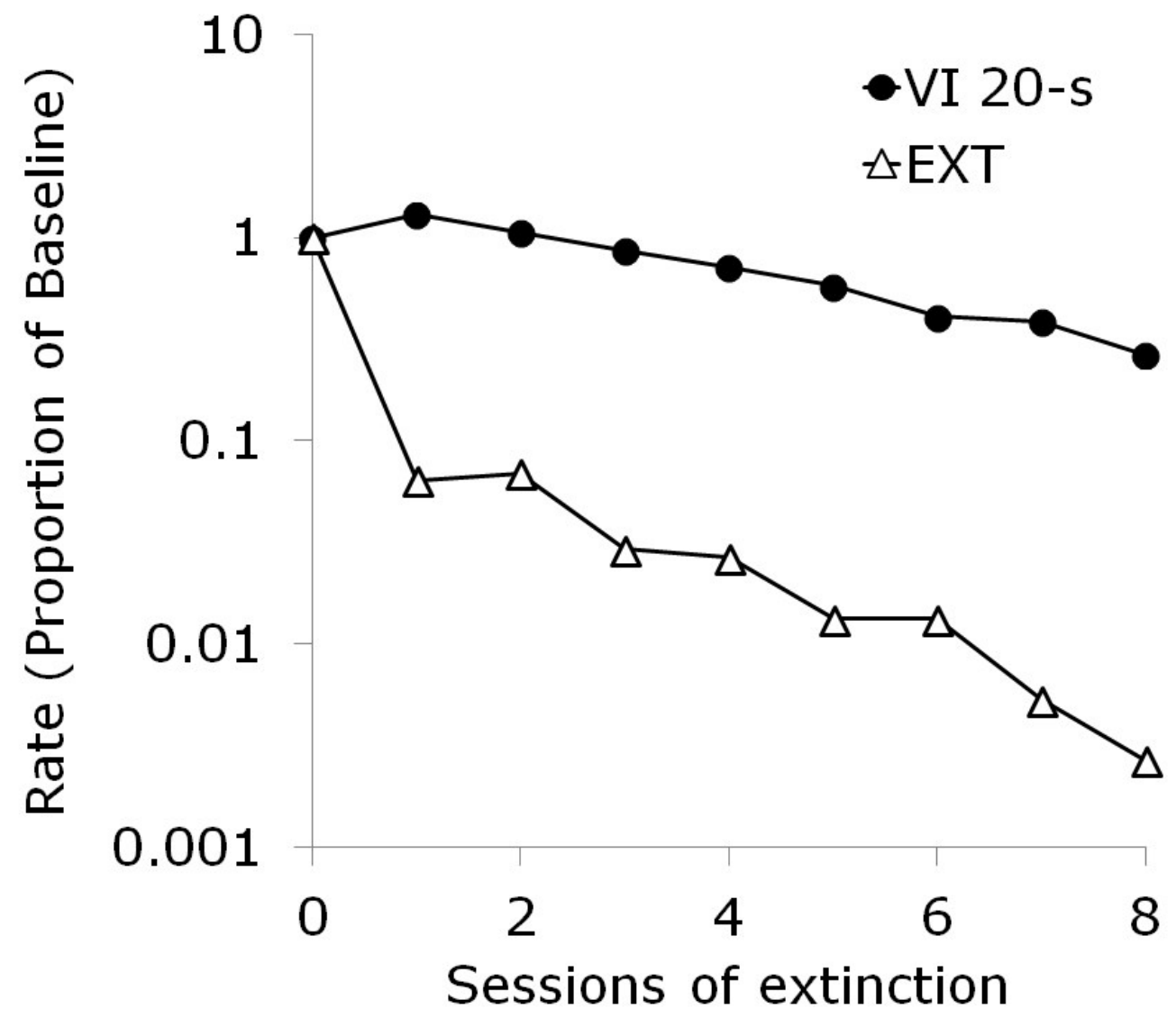

Figura 10. Taxa de resposta em um dos componentes de um esquema múltiplo durante sucessivas sessões de extinção. Os círculos preenchidos representam a condição na qual o segundo componente foi associado com VI 20-s, enquanto os triângulos abertos representam a condição na qual o segundo componente também era um esquema de extinção. Os dados estão expressos como proporções da linha de base (Sessão 0). 


\section{CAPÍTULO 4}

Controle por Esquemas e Timing: Avançando para a Integração de Teorias 


\section{Integrando Teorias}

Como vimos, a máquina-MPR pode partir de processos comportamentais muito simples para simular o responder operante. Foi demonstrado que esse responder é realista sob várias condições experimentais, e sob diferentes níveis de análise. Quando confrontada com esquemas de intervalo e de razão, simples e múltiplos, ela foi capaz de produzir com coerência (a) distribuições de IRT, (b) padrões de resposta intra-sessão, (c) relações molares entre taxa de resposta e de reforçamento, (d) contraste comportamental, (e) os padrões intrasessão de resposta subjacentes ao contraste comportamental, e (f) a desaceleração da extinção por reforçamento alternativo. Ademais, a máquina foi capaz de fazer isso com virtualmente as mesmas configurações (valores de parâmetros) ao longo de todos os experimentos, e essas configurações foram baseadas em estimativas frequentemente encontradas na literatura.

A despeito de seu amplo alcance, a máquina-MPR está longe de ser um modelo universal do comportamento operante. Existe uma miríade de condições experimentais para as quais o mecanismo, como se apresenta, seria simplesmente incapaz de responder. Uma rápida inspeção visual da Figura 1 torna claro que a máquina não está equipada para lidar com muitos dos paradigmas que residem na fundação da análise experimental do comportamento (como os esquemas concorrentes, por exemplo). Obviamente, isso não é um problema. Nenhum modelo precisa ser capaz de abarcar fenômenos além do domínio para o qual ele foi originalmente construído. O que torna a máquina-MPR útil é que, como demonstrado no capítulo anterior, ela pode facilmente incorporar mais engrenagens para expandir seu escopo. Nesse sentido, o modelo serve como uma plataforma para integração de teorias.

O custo de adicionar mais engrenagens é o número aumentado de parâmetros livres. No Capítulo 3, para modelar o comportamento em esquemas múltiplos, nós introduzimos o parâmetro $\alpha$ para endereçar a extinção/desacoplamento e $\gamma$ para abarcar os efeitos da privação. Juntamente com a formulação básica, terminamos com muito mais parâmetros livres do que seria esperado de um modelo desenhado especificamente para modelar o responder em esquemas múltiplos.

Essa falta aparente de parcimônia, no entanto, pode ser justificada por duas razões principais. Primeiramente, mesmo que pudéssemos ter um modelo mais simples para explicar especificamente o comportamento em esquemas múltiplos, esse modelo não nos diria nada acerca da relação entre os fenômenos que emergem nesses esquemas e todos os outros produzidos exatamente pelo mesmo sujeito sob condições experimentais diferentes. O rato 
que exibe contraste comportamental sob esquemas múltiplos é o mesmo que obedece à hipérbole de Herrnstein sob esquemas VI simples - e, se estamos buscando um modelo integrado desse animal integrado, uma coleção de parâmetros livres parece ser o preço a ser pago. Em segundo lugar, muitos dos parâmetros da máquina-MPR assumem valores prédefinidos, conhecidos e consistentes, mensuráveis com diferentes procedimentos (veja, por exemplo, a discussão sobre como o parâmetro $C$ converge com as estimativas de Killeen (1994) para $\rho$ sob esquemas de intervalo variável). Então, de fato, muitos desses parâmetros se comportam mais como constantes do que como parâmetros livres propriamente ditos.

No capítulo anterior, experimentamos adicionar blocos construtivos simples à máquina-MPR. Aqui, daremos um grande passo adiante, usando o modelo como uma plataforma para integração teórica total.

\section{Temporizando a Máquina-MPR}

Um importante conjunto de condições sob o qual o comportamento da máquina-MPR se provaria irrealista seria aquele no qual o animal é obrigado a prever a duração de um intervalo. Considere, por exemplo, os esquemas de intervalo fixo nos quais a primeira resposta após $T$ segundos se passarem é reforçada, enquanto qualquer resposta emitida antes disso é sem efeito. Um sujeito experimental respondendo em estado estável sob essa condição exibirá uma baixa probabilidade de emissão da resposta-alvo no começo de cada trial, aumentando gradualmente sua taxa de resposta à medida que o cronômetro se aproxima da oportunidade de reforçamento, gerando o conhecido padrão escalopado FI (Ferster \& Skinner, 1957). Essa capacidade, conhecida como timing, parece requerer algum tipo de discriminação temporal que está completamente ausente da máquina-MPR. Exposta ao mesmo procedimento, a máquina-MPR seria certamente sensível a mudanças na taxa de reforçamento, e ajustaria seu comportamento de acordo, mas seu responder emergiria como um fluxo constante de respostas-alvo, com nenhuma correlação com o tempo dentro do intervalo.

Diferentes modelos de timing já foram apresentados, como a Teoria da Expectativa Escalar (SET; Gibbon, Church \& Meck, 1984), a Teoria Comportamental do Timing (BeT; Killeen \& Fetterman, 1988), a Learning-to-Time (LeT; Machado, 1997), e o modelo das Múltiplas Escalas de Tempo (MTS; Staddon \& Higa, 1999), para citar alguns. Como 
Machado, Malheiro e Erlhagen (2009) observaram, comparar esses modelos uns com os outros tem se provado um processo espinhoso - algo que está além do escopo deste estudo. $\mathrm{O}$ nosso propósito aqui é examinar como a máquina-MPR, como plataforma, pode ser integrada com outros modelos e teorias para abarcar fenômenos além de seu alcance original. E, ao fazer isso, nós também buscamos oferecer uma visão de como performances diferentes sob condições experimentais diferentes podem ser produzidas por um mecanismo simples e totalmente integrado.

Para esse propósito, escolhemos a Learning-to-Time (LeT) como nosso modelo de timing. Uma das razões para essa escolha é histórica-teórica. A LeT foi derivada da BeT (Killeen \& Fetterman, 1988). Essa teoria, por sua vez, foi fundada sobre a realização de que "o comportamento muda ao longo do intervalo entre reforçadores" e que "estímulos que sinalizam reforçadores engendram respostas" - a mesma realização que inspirou o modelo de excitação embutido na MPR (Killeen, Hanson, \& Osborne, 1978). Então, a LeT e a MPR compartilham as mesmas raízes conceituais, o que torna qualquer tentativa de integração muito mais natural. Além disso, a própria arquitetura da LeT a torna adequada para tratamento como um módulo de uma estrutura maior.

\section{Um Breve Panorama da LeT}

A estrutura da LeT consiste em três componentes principais: estados comportamentais serialmente organizados, um vetor de links associativos conectando os estados comportamentais à resposta operante e a resposta operante propriamente dita, como ilustrado na Figura 11 (Machado, 1997). A premissa central do modelo é que um marcador temporal, como comida ou outro preditor confiável de reforçamento, inicia uma propagação de ativação ao longo de uma série de estados comportamentais. A ativação $X$ do estado $n$ no momento $t$ é dada pelas seguintes equações diferenciais:

$$
\begin{aligned}
& \frac{d}{d t} X(t, 0)=-\lambda X(t, 0), \\
& \frac{d}{d t} X(t, n)=\lambda X(t, n-1)-\lambda X(t, n), \quad n \geq 1,
\end{aligned}
$$

onde $\lambda$ é o parâmetro que controla a taxa na qual a ativação se propaga entre os estados. As condições iniciais do sistema são dadas por: 


$$
\begin{aligned}
& X(0,0)=1, \\
& X(0, n)=0, \quad n>0 .
\end{aligned}
$$

Machado (1997) ofereceu uma analogia que torna o significado dessas equações mais claro. Considere uma cascata de compartimentos de água, todos fisicamente idênticos e cada um com um orifício no fundo. Na condição inicial $(t=0)$, o primeiro compartimento $(n=0)$ está cheio, enquanto todos os outros $(\mathrm{n}>0)$ estão vazios (Equação 32). Como cada compartimento tem um orifício, a água flui para fora do primeiro compartimento, como descrito pela Equação 29. Os compartimentos seguintes têm uma dinâmica mais complicada, ilustrada pela Equação 30: eles recebem água do compartimento acima $(\lambda X(t, n-1))$ ao mesmo tempo em que perdem água para o compartimento abaixo $(-\lambda X(t, n))$. Nessa analogia, $\lambda$ estaria relacionado ao diâmetro do orifício.

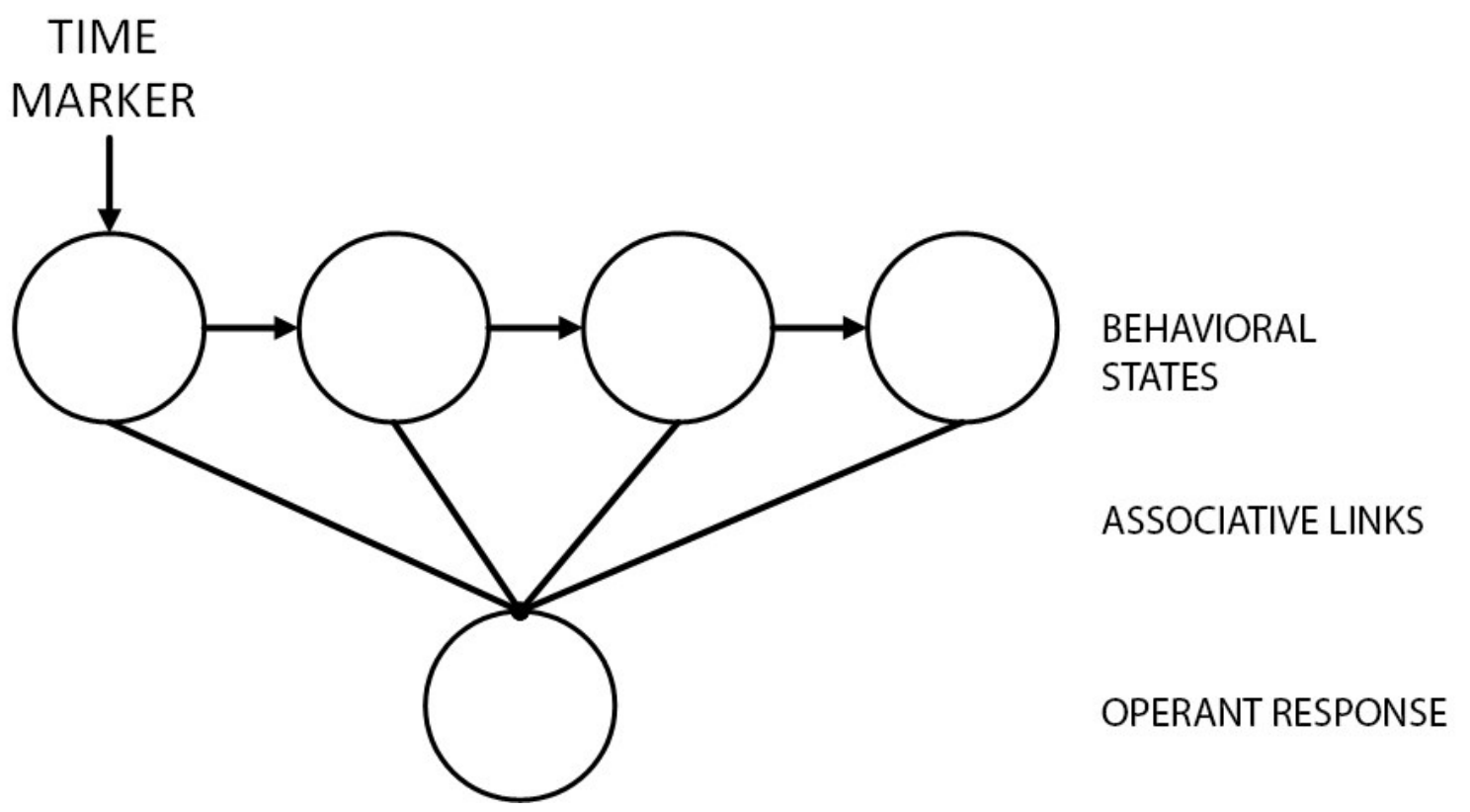

Figura 11. Componentes e arquitetura da LeT. Um estímulo como comida funciona com um marcador temporal, iniciando uma propagação de ativação ao longo dos estados comportamentais. A ativação da cada estado, multiplicada pelo peso da associação com a resposta operante, determina sua força. A aprendizagem ocorre através da mudança sistemática dos pesos. 
Mas como os estados comportamentais ganham controle sobre a classe operante? A LeT assume que, durante a extinção (i.e., quando o reforçador não está disponível), a força da associação entre cada estado e a resposta operante, dada por $W(t, n)$, decresce em tempo real. A quantidade dessa mudança, no entanto, depende de quanto cada estado está ativo no tempo $t$. Estados muito ativos têm seus links amplamente afetados, enquanto estados pouco ativos mantêm a força de suas associações quase inalteradas, como descrito pela seguinte equação:

$$
\frac{d}{d t} W(t, n)=-\alpha X(t, n) W(t, n), \quad \alpha>0
$$

onde $\alpha$ é um parâmetro que controla a taxa de aprendizagem.

Por outro lado, quando o reforçador está disponível, a força de associação entre cada estado e a resposta operante aumenta de acordo com a mesma regra: estados muito ativos têm suas conexões substancialmente aumentadas enquanto estados pouco ativos sofrem mudanças menores no peso de seus links:

$$
\frac{d}{d t} W(t, n)=\beta X(T, n)[K-W(t, n)], \quad(\beta>0, t \geq T)
$$

onde $K$ está relacionado ao valor de incentivo do reforçador (determinando a assíntota até a qual o peso dos links associativos pode aumentar), $T$ é o momento no qual o reforçador é entregue e $\beta$ é a taxa de aprendizagem. Tomadas juntas, as Equações 33 e 34 mostram que a força de cada link associativo pode se aproximar de 0 durante a extinção e de $K$ durante o reforçamento, sempre em uma taxa proporcional à ativação de seus estados correspondentes.

Dadas as equações para a ativação dos estados (29 a 32) e para a atualização dos links (33 e 34), a equação para a taxa de respostas $(B)$ no momento $t$ é simples:

$$
B(t)=\varphi \sum_{n-1} X(t, n) W(t, n), \quad \varphi>0
$$

onde $\varphi$ é um parâmetro de escala com unidade 1/s. O que a Equação 35 estabelece é que a taxa de resposta a cada momento do intervalo é determinada pela função discriminativa de todos os estados (como representado pela força de seus links associativos correspondentes) ponderada pelas respectivas ativações. 


\section{Concatenando a LeT e a Máquina-MPR}

Para mesclar a LeT e a máquina-MPR, precisaremos fazer algumas modificações na formulação original da LeT: inicialmente, vamos reinterpretá-la em termos de probabilidade de resposta; depois, alteraremos a regra para a atualização dos pesos.

\subsection{Probabilidade de resposta}

Um olhar atento às Equações 29 a 32 revela que a quantidade total de ativação no sistema da LeT nunca é maior do que 1 (na analogia dos compartimentos de água, esta é a quantidade de água inicialmente no primeiro compartimento, que alimenta todos os outros abaixo). Segue-se que, se também mantivermos a assíntota dos pesos como 1 (i.e., $K=1$ ), o somatório da ativação de todos os estados, cada qual multiplicado por seu respectivo peso de conexão, nunca excederá 1 :

$$
\sum_{n-1} X(t, n) W(t, n) \leq 1, \quad K=1
$$

Isso torna essa quantidade adequada para uma reinterpretação em termos de probabilidade de resposta: à medida que os estados fortemente associados com a classe operante se tornam mais ativos, a probabilidade de resposta se aproxima de 1; quando os estados fracamente associados com a classe operante se ativam, a probabilidade de resposta se aproxima de 0.

\subsection{Atualização dos Pesos}

A LeT assume que sempre que um reforçador está ausente, a força da associação entre os estados e a resposta operante decresce continuamente (Equação 33). Ela também postula que a apresentação de um reforçador é suficiente para fortalecer os links (Equação 34). Como apresentadas, as equações de atualização dos pesos não dizem nada sobre contingências operantes. Em outras palavras, a apresentação ou ausência de um reforçador são condições suficientes para a atualização dos pesos, independentemente do comportamento do sujeito. Nesse sentido, a LeT original parece descrever um processo de aprendizagem relacionado a alguma forma de condicionamento respondente. 
Para integrar a LeT à máquina-MPR, iremos propor modelos diferentes para a atualização dos pesos. Em vez de equações em tempo real e contínuo, iremos simplesmente assumir que sempre que um reforçador se segue a uma resposta operante os links são fortalecidos proporcionalmente à ativação dos estados correspondentes:

$$
w_{n}^{\prime}=w_{n}+\left[w_{n} x_{n}\left(1-w_{n}\right)\right]
$$

onde $w_{n}{ }^{\prime}$ é o peso atualizado do link entre o estado $n$ e a resposta operante, $w_{n}$ é o peso atual e $x_{n}$ é a ativação desse estado. O termo $\left(1-w_{n}\right)$ define 1 como a assíntota. Quando uma resposta operante falha em produzir um reforçador, os links são enfraquecidos da mesma forma:

$$
w_{n}{ }^{\prime}=w_{n}-\left(x_{n} w_{n}\right)
$$

Essas equações são proximamente relacionadas às Equações 33 e 34 . A maior diferença reside no fato de que estas não são equações de tempo real que operam independentemente do comportamento do sujeito: elas são regras de atualização que agem pontualmente após cada sucesso ou fracasso da resposta-alvo em produzir um reforçador. A premissa básica é que o condicionamento operante desempenha um papel central quando um animal está aprendendo a temporizar um intervalo.

\section{Reconstruindo a Máquina}

Após reinterpretar a LeT em termos de probabilidade de resposta, e com novos modelos de atualização dos pesos estabelecidos, estamos prontos para reconstruir a máquinaMPR. A concatenação dos dois modelos resulta na arquitetura apresentada na Figura 12.

Os blocos construtivos básicos do mecanismo são prontamente distinguíveis: podemos ver o gerador Poisson de respostas, os controles de excitação e saciação e o decisor probabilístico de resposta-alvo/não alvo. A diferença reside no que determina a probabilidade de uma resposta-alvo $(C)$. Na máquina-MPR original (Figura 1), a probabilidade de resposta é determinada pelos nossos modelos de memória e acoplamento. Aqui, $C$ é simplesmente a soma ponderada dos estados ativos:

$$
C=\sum\left(x_{n} w_{n}\right)
$$




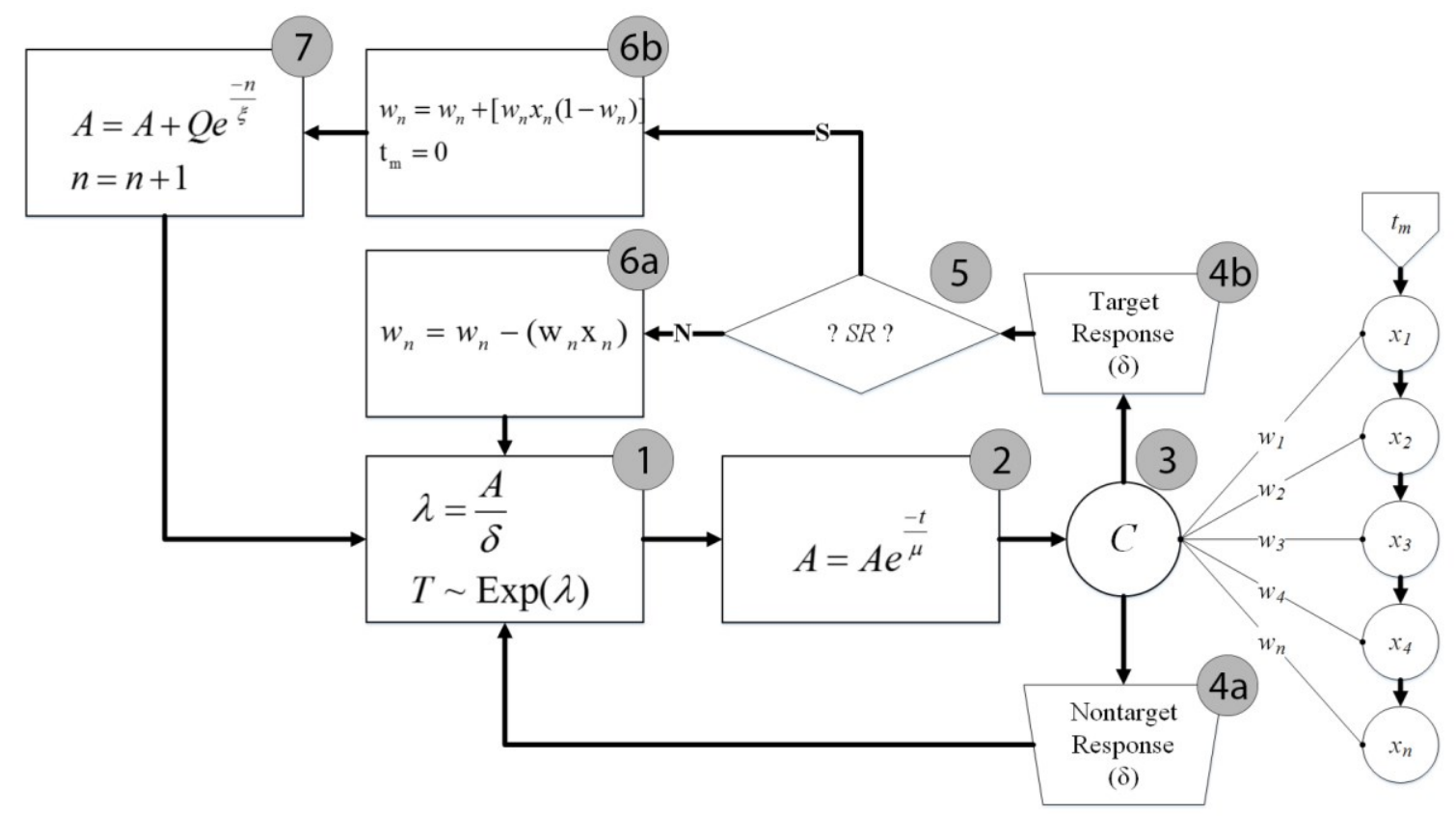

Figura 12. A máquina-MPR mesclada com uma versão da LeT.

Para calcular a ativação do estado $n$ no momento $t$, nós usamos a solução das Equações 29-32 (Machado, 1997), que é dada por:

$$
x(t, n)=\frac{e^{-\lambda t}(\lambda t)^{n}}{n !}
$$

A despeito a complexidade aparente da máquina, ela funciona de uma maneira bastante direta. O processo se inicia no Box 1, onde uma resposta é gerada por um processo de Poisson com taxa proporcional à excitação $(A)$ do sujeito. Durante o tempo que o gerador leva para emitir uma resposta, a excitação decai, então atualizamos $A$ no Box 2. Até este momento, a máquina ainda não decidiu se a resposta gerada é uma resposta-alvo ou não. $\mathrm{O}$ Box 3 é responsável por essa decisão: ele computa a probabilidade de uma resposta-alvo $(C)$ como o somatório da ativação de todos os estados, cada qual ponderado pelo peso de sua associação com a classe operante (veja a Equação 39). A ativação de cada estado neste momento em particular é dada pela Equação 40. Se a resposta é definida como não alvo (Box $4 a$ ), a máquina pausa por $\delta$ segundos (o tempo necessário para a resposta ser performada) e depois retorna ao Box 1, onde permanece até que uma nova resposta possa emergir do gerador Poisson. Por outro lado, se a resposta é definida como uma resposta-alvo (Box 4b), ela pode ou não produzir um reforçador, dependendo dos requisitos do esquema (Box 5). Se nenhum reforçador é produzido (Box 6a), o peso de cada estado é reduzido proporcionalmente à sua 
ativação, como definido pela Equação 38. Ao contrário, se um reforçador é produzido (Box 6b), o peso de cada estado é proporcionalmente aumentado (Equação 37) e, como o reforçador funciona como um marcador temporal, a propagação de ativação pelos estados comportamentais é reiniciada ( $t=0$ na Equação 40). Por fim, como o Box 7 mostra, o reforçador também tem o efeito de impulsionar a excitação e incrementar a saciação. A máquina volta ao Box 1 e um novo ciclo se inicia. Como essa máquina funciona como uma máquina-MPR temporizada, ela será chamada daqui em diante de máquina-tMPR - ou simplesmente $t$ MPR.

\section{Rodando a $t$ MPR}

A literatura de timing sempre foi prolífica em gerar novos paradigmas experimentais. Por conseguinte, o arranjo de condições sob as quais nós podemos testar a $t$ MPR é vasto, e inclui tarefas como o procedimento pico, os esquemas FI e os experimentos de bissecção temporal. Como o objetivo do presente estudo é integrar um modelo de controle por esquemas com um modelo de timing, testaremos a máquina sob um conjunto de esquemas FI. Em virtude de seus modelos concatenados, ela deverá ser capaz de simular fenômenos importantes no campo do controle por esquemas (como a hipérbole de Herrnstein) assim como propriedades relevantes no campo do controle temporal (como a correlação da taxa de resposta com o tempo dentro do intervalo e as propriedades escalares do comportamento de timing).

\subsection{Experimento 6: Esquemas de intervalo fixo}

Para este experimento, executamos a $t \mathrm{MPR}$ sob quatro esquemas FI diferentes (FI 15-s, FI 30-s, FI 60-s e FI 120-s). Os parâmetros foram todos fixados em seus valores padrão $(Q=0.15, \mu=6 \mathrm{~min}, \delta=0.6 \mathrm{~s}$ e $A$ inicial $=0.15)$. O parâmetro $\lambda$, a taxa que controla a propagação de ativação entre os diferentes estados comportamentais, foi fixado em 0.1. Para simplificar, sob todas as condições a taxa de saciação $\xi$ foi fixada em $\infty$, simulando uma condição na qual nenhuma saciação ocorre. Cada condição compreendeu 3 sessões, e cada sessão durou 500 minutos (como a saciação foi cancelada, os padrões de resposta não são afetados por sessões tão longas). Em cada sessão, todos os pesos foram inicialmente fixados em 0.8. Os dados médios das 3 sessões em cada condição estão plotados nas Figuras 13 a 15. 


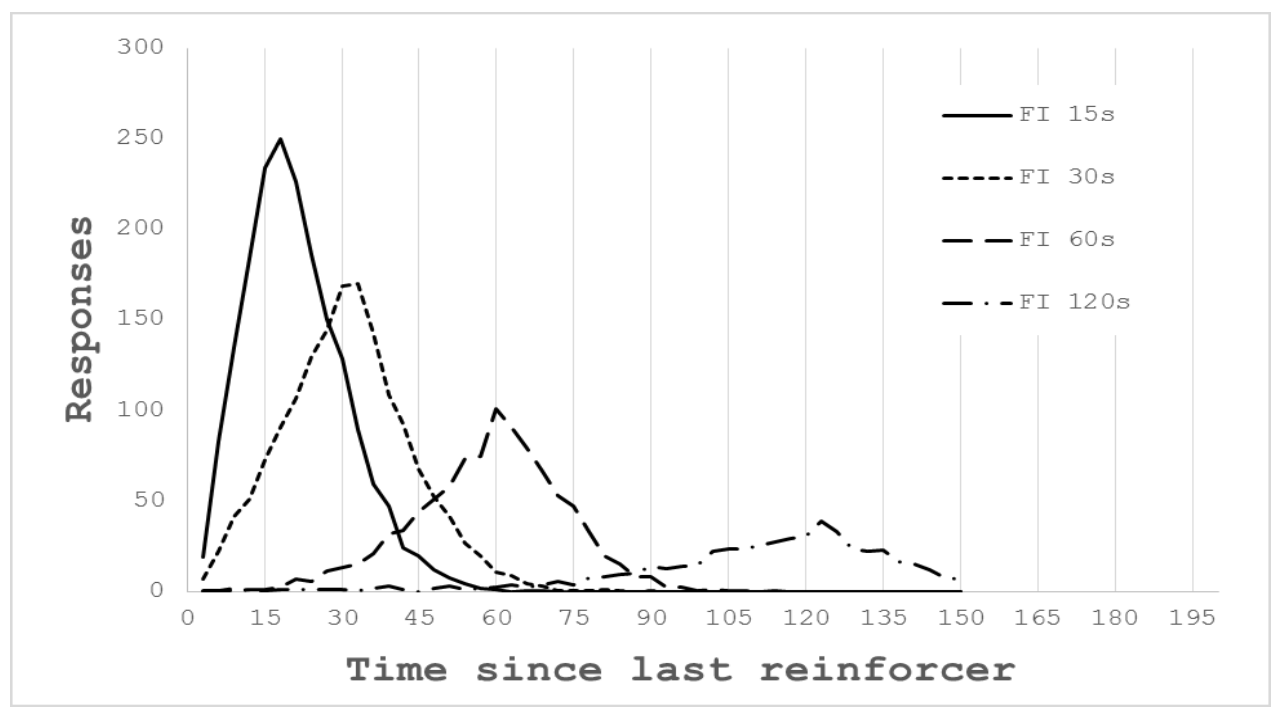

Figura 13. Distribuição das respostas simuladas da máquina-tMPR em função do tempo desde o último reforçador em diferentes esquemas FI.

A Figura 13 mostra a distribuição das respostas-alvo da máquina-tMPR em cada condição em função do tempo desde o último reforçador. A primeira observação é que, com essa nova arquitetura, o mecanismo foi capaz de aprender as regularidades temporais dos esquemas de reforçamento. Em vez do fluxo contínuo de respostas que seria esperado da máquina-MPR original, nós agora podemos testemunhar uma clara organização temporal dos padrões de resposta, com poucas respostas-alvo ocorrendo no início de cada intervalo, um aumento no responder à medida que o intervalo transcorre e um pico de respostas no momento do reforçador programado. Também é possível ver que os intervalos maiores produziram timing menos preciso, como seria esperado de animais reais (Dews, 1970). A Figura 14 mostra que quando a taxa de resposta média ao longo do intervalo é plotada em eixos normalizados, as curvas das condições 15 -s e 30-s se sobrepõem - uma demonstração da propriedade escalar. O mesmo acontece (menos precisamente) com as curvas das condições 60-s e 120-s. A razão pela qual as curvas das condições 15 -s e 30 -s não se sobrepõem às curvas de 60-s e 120-s reside em uma simplificação da LeT. Machado (1997) demonstrou que em intervalos entre reforçadores (IRIs) maiores, o parâmetro $\lambda$ pode cair até uma ordem de magnitude, refletindo uma perda relativa do controle temporal em esquemas mais longos. Para endereçar este fenômeno, ao ajustar seu modelo aos dados de Dews (1970), Machado tornou $\lambda$ inversamente proporcional aos IRIs. Aqui, para simplificar, mantivemos $\lambda$ constante em todas as condições, tornando o timing em intervalos maiores irrealisticamente preciso. 


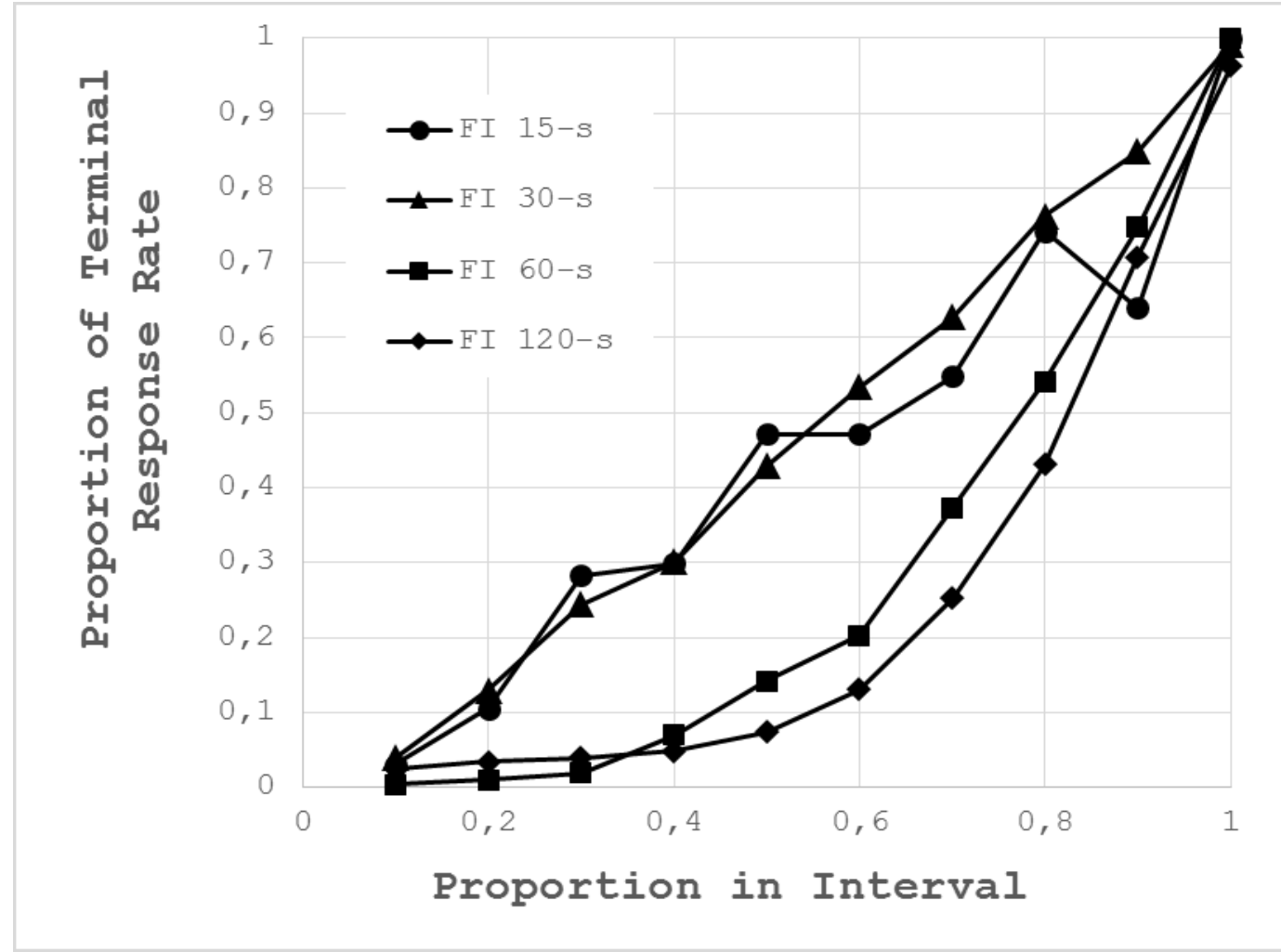

Figura 14. Proporção da taxa de resposta terminal em função do tempo relativo dentro do intervalo em diferentes esquemas FI. Os dados foram gerados pela máquina- $t$ MPR.

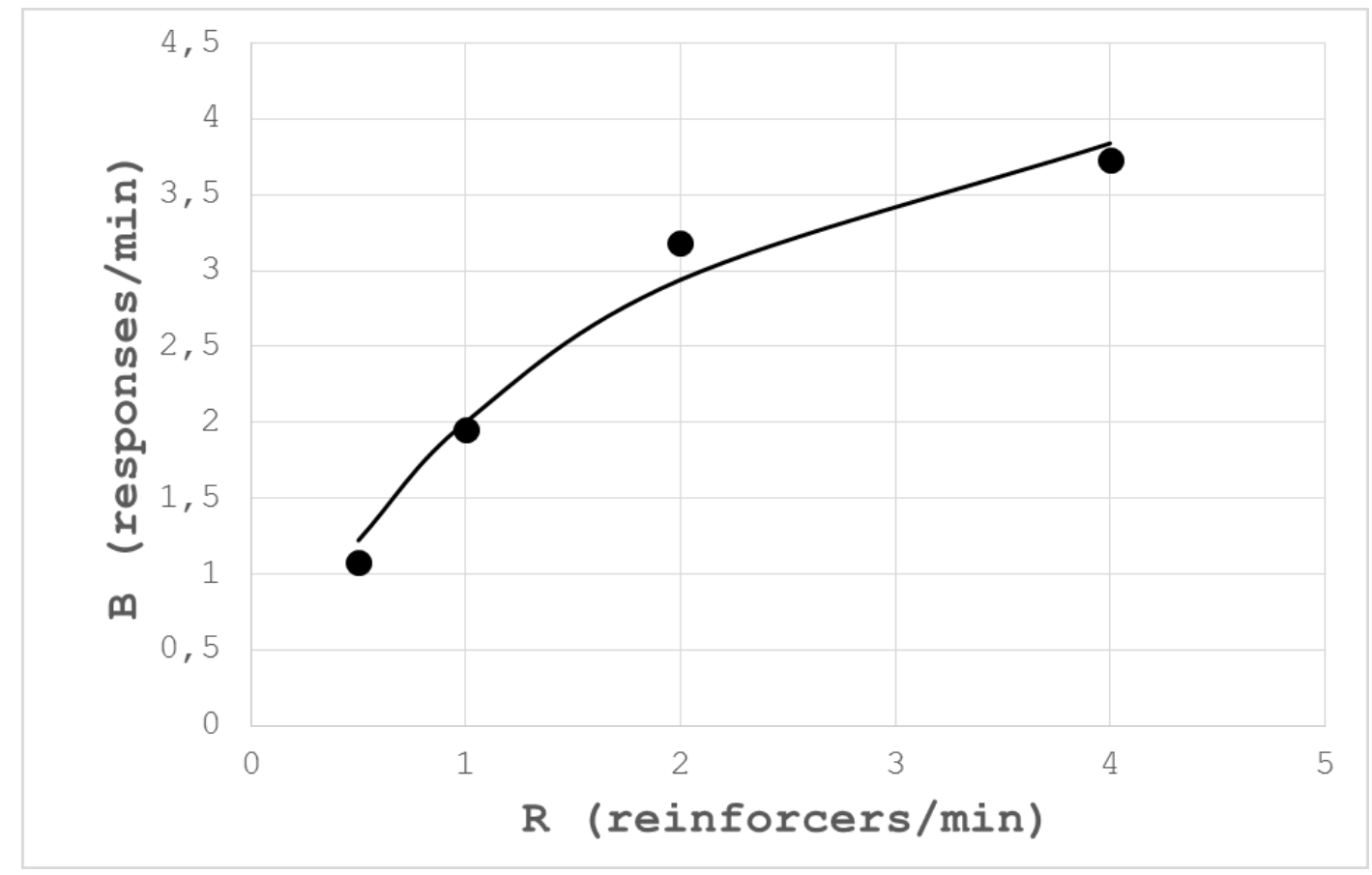

Figura 15. Taxa de resposta em função da taxa de reforçamento sob diferentes esquemas FI. Os dados foram gerados pela $t$ MPR, e a curva é a hipérbole clássica de Herrnstein (1970). 
Então, o modulo LeT foi capaz de transformar a $t$ MPR em um modelo coerente de controle temporal do comportamento operante. Mas e as propriedades molares do controle por esquemas? Os dados gerados pela $t$ MPR se conformam às propriedades molares clássicas do comportamento controlado por esquemas? Para responder essa pergunta, a Figura 15 mostra a taxa de resposta agregada em função da taxa de reforçamento programada, com a hipérbole de Herrnstein $\left(1970 ; B=k R /\left(R+R_{e}\right)\right)$ ajustada aos dados. Os valores para $k$ e $R_{e}$ foram 5,5 e 1,8 , respectivamente. Como podemos ver, além de realistas quando analisados no nível intraintervalo, os dados simulados também são precisos quando analisados em níveis mais molares. No nível intra-intervalo, a $t$ MPR se provou capaz de produzir timing. No nível molar, ela provou que passa pelos processos motivacionais que dirigem o comportamento controlado por esquemas. Nesse sentido, a despeito das limitações já discutidas (como o parâmetro $\lambda$ fixo) e todos os outros inerentes a qualquer modelo, a máquina- $t$ MPR serviu ao seu propósito de ilustrar o potencial da máquina-MPR como uma plataforma robusta para integração de teorias. 


\section{DISCUSSÃO GERAL}

Anderson et al. (2004), escreveu para a Psychological Review que

A psicologia, como outras ciências, tem visto um movimento inexorável no sentido da especialização. Isso é visto na proliferação de jornais especializados no campo, e também na proliferação de artigos de tópicos especiais neste jornal, que deveria servir como um lugar no qual as ideias da psicologia se encontram. Embora existam boas razões para pelo menos algumas das propostas de módulos cognitivos especializados, existe algo insatisfatório no resultado - a imagem da mente como um conjunto desconexo de especialidades mentais. Pode-se perguntar: "como tudo isso é reunido novamente?" (p. 1036).

Embora ele esteja se referindo ao aumento da fragmentação no campo das ciências cognitivas, o mesmo pode ser dito sobre a análise experimental do comportamento. Antes estudados como fenômenos proximamente relacionados, tópicos como discriminação de estímulos, controle por esquemas, timing, atraso no reforçamento, omissão de reforço, interação entre esquemas e escolha - para citar alguns - têm se tornado áreas de pesquisa quase independentes, com muito pouco para ensinar ou aprender umas com as outras. Com o surgimento de modelos matemáticos muito estreitos e complexos em cada um desses campos nas últimas décadas, o isolamento alcançou o paroxismo. Agora, além do crescente encapsulamento dos nossos projetos de pesquisa, estamos enfrentando o encapsulamento de nossas terminologias - o próprio laço que define os analistas do comportamento como um grupo.

Essa tendência, naturalmente, traz consequências adversas para a área. A primeira delas é o risco da perda de relevância na arena mais ampla das ciências comportamentais. Se não podemos nos comunicar entre nós mesmos, é provavelmente ainda mais difícil que nos comuniquemos com aqueles de outras tradições.

A segunda consequência adversa é o crescente esoterismo de nossas teorias. Como cada área de pesquisa está debruçada sobre seus próprios assuntos, diversos pesquisadores sentem-se livres para introduzir construtos e modelos - e para assumir premissas - que não encontram nenhum outro espaço na disciplina. Nesse contexto, um grupo de pesquisa se satisfaz em construir um modelo que endereça seus problemas específicos, mesmo que as premissas desse modelo não façam sentido fora daquele domínio restrito. Poling (2010) notou esta tendência, expressando sua preocupação com o que ele chamou de "análise esotérica do comportamento". 
A terceira consequência adversa do isolamento teórico - e, talvez, a mais importante é que ele prejudica profundamente nossas tentativas de compreender o comportamento.

Imagine um rato dentro de uma câmara operante, respondendo sob um esquema de razão variável. Seu comportamento é marcado por um fluxo contínuo de respostas, em uma taxa que mantém uma relação previsível com a taxa de reforçadores programados. Um pesquisador trabalhando com modelos de controle por esquemas não terá problemas em explicar os dados que estamos obtendo. Ele falará sobre igualação, a lei do efeito, e possivelmente usará a hipérbole de Herrnstein para nos agradar com um elegante ajuste de curva. Mas o que acontece se, de repente, nós tornarmos o intervalo entre os reforçadores mais previsível, como em um esquema de intervalo fixo? O responder do rato irá gradualmente se ajustar a essa nova contingência, e nós começaremos a notar um padrão periódico de comportamento, com baixa probabilidade de resposta imediatamente após a apresentação de um reforçador e uma taxa de resposta crescente à medida que o intervalo avança. Se nos voltarmos ao teórico do controle de esquemas em busca de uma explicação para esses fenômenos, o encontraremos menos falante. A lei do efeito e a hipérbole de Herrnstein silenciam-se sobre esse tipo de comportamento temporizado. Precisaremos agora de uma caixa de ferramentas diferente, talvez carregada com termos como pacemaker, acumulador e comparador. Se o objetivo é termos uma curva diferente que se ajuste a cada novo conjunto de dados que conseguirmos coletar, estaremos bem. Mas se nós estivermos tentando entender o que realmente está ocorrendo dentro da câmara operante, claramente temos um problema. Afinal, onde estavam o acumulador e o comparador quando o rato estava respondendo em um esquema de razão? E qual exatamente é o lugar da igualação e do reforçamento alternativo neste novo contexto de reforço previsível? Como nós temos apenas um rato, e como o rato não tem nenhuma ideia sobre o que é um esquema FI, devemos presumir a existência de um sistema integrado que (a) respondeu a uma taxa elevada e estável na primeira condição, (b) detectou de alguma forma a mudança de condição, e (c) respondeu em uma taxa baixa e periódica na segunda condição. Na ausência de um modelo dinâmico e integrativo desse sistema, somos deixados com fotografias desconexas de como esse mecanismo se parece sob uma miríade de diferentes paradigmas.

Anderson et al. (2004) abordou o problema do isolamento das subáreas nas ciências cognitivas desenvolvendo uma arquitetura cognitiva chamada Active Control of Though (ACT-R). Essa arquitetura é simplesmente uma hipótese sobre como os "componentes da mente humana" trabalham em conjunto para produzir cognição coerente. Com isso, ele 
integrou modelos estabelecidos de percepção visual, conhecimento procedural, conhecimento declarativo, linguagem, memória de trabalho e assim por diante (para uma introdução à ACT$\mathrm{R}$, recomendamos a leitura de Anderson, 1996). Uma das características interessantes dessa arquitetura é que sua construção modular permite a substituição dos modelos componentes sem prejuízo para a teoria geral. Se um modelo melhor de memória de trabalho surge na literatura, por exemplo, o módulo de memória de trabalho da ACT-R pode ser imediatamente atualizado para incorporar os desenvolvimentos mais recentes.

Essa estratégia tem estimulado a formação de uma comunidade de pesquisa ampla e diversa em torno da ACT-R. Como a arquitetura envelhece bem, não há risco em um compromisso de longo prazo com ela. E, como ela é flexível o bastante para articular diferentes tipos de objetivos de pesquisa, todos são bem-vindos para participar da conversa. Finalmente, sua implementação em um sistema computacional aberto facilita a colaboração na forma de uma construção incremental. Como resultado, o website da ACT-R ((http://actr.psy.cmu.edu) lista centenas de artigos de pesquisa apresentando aplicações da arquitetura a problemas que vão desde o processamento verbal de analogias e metáforas até a tomada de decisões em grupo. No momento em que escrevemos, o diretório de colaboradores lista 103 instituições, de 17 países.

Acreditamos firmemente que a análise experimental do comportamento teria muito a ganhar de um esforço similar de integração. O objetivo, obviamente, não é substituir os modelos sendo desenvolvidos em cada subárea, mas encorajar os pesquisadores a pensar seus temas de pesquisa no contexto de um framework mais amplo - e desafiá-los a formular suas teorias em termos que façam sentido para o laboratório na porta ao lado.

Nós quebramos o comportamento em pedaços e mergulhamos profundamente em seus menores segredos - este é o objetivo de uma análise do comportamento. Mas agora pode ser o momento no qual nós devemos começar a colar as peças de volta para obter uma imagem mais completa da direção que estamos tomando - esse seria o propósito de uma síntese comportamental.

Neste estudo, nós apresentamos nossa melhor hipótese acerca de como uma arquitetura comportamental deve ser. A despeito dos detalhes matemáticos, os princípios são simples, não esotéricos, e todos emprestados da MPR. Em resumo, as premissas são: 
a) os reforçadores excitam o comportamento, no sentido de que sua apresentação aumenta a probabilidade de respostas-alvo e não alvo;

b) as contingências de reforçamento direcionam o comportamento, no sentido que elas mudam a probabilidade relativa das respostas-alvo versus não alvo;

c) o tempo limita o comportamento, impondo um teto à taxa de resposta.

As premissas subsidiárias também são simples:

d) durante um período de ausência de reforçadores, a excitação se dissipa;

e) as propriedades excitatórias dos reforçadores decrescem ao longo de apresentações sucessivas (por meio de processos como saciação e habituação).

Colocadas juntas, essas premissas foram um núcleo computacional que gera respostasalvo e não alvo de acordo com o nível de excitação, e que balanceia a proporção de respostasalvo e não alvo de acordo com a história prévia de reforçamento. As respostas-alvo que cumprem o critério do esquema produzem um reforçador, que realimenta o sistema com excitação adicional ao mesmo tempo em que reduz a capacidade do próximo reforçador fazer o mesmo.

Embora esse design simples da máquina tenha se provado capaz de simular uma ampla variedade de fenômenos, sua verdadeira utilidade reside em quão facilmente ele pode incorporar extensões. No Capítulo 3, modelos muito resumidos e tentativos de controle de estímulos, desacoplamento (extinção) e privação foram suficientes para estender o alcance da máquina-MPR ao domínio dos fenômenos complexos dos esquemas múltiplos.

No entanto, apenas no Capítulo 4 a arquitetura realizou plenamente seu propósito. Ao equipar a máquina-MPR com um modelo de timing, nós fomos impelidos a (a) selecionar um modelo que pudesse se comunicar mais facilmente com as premissas centrais, (b) repensar todos os componentes em termos de como eles poderiam ser traduzidos para uma linguagem compartilhada, (c) expandir e reformular os modelos para que eles pudessem ser concatenados, (d) pensar sobre como diferentes processos comportamentais se desenvolvem em paralelo, em tempo real, e como eles interagem uns com os outros para produzir comportamento coerente e adaptativo. É dispensável enfatizar como todos esses exercícios são saudáveis para uma ciência ainda em processo de maturação. 
Os modelos componentes, devemos reconhecer, sofreram alguns arranhões e contusões no processo. Terminamos com uma versão da LeT que é mais probabilística - e que, com suas novas regras para atualização dos pesos, tem um ar mais operante do que a formulação original. Mas isso não é necessariamente ruim: um casamento envolve concessões, e para fazer parte de uma grande família às vezes temos que deixar de lado algumas de nossas idiossincrasias.

Alguém poderia argumentar contra a fusão dos modelos, já que isso aumenta o número de parâmetros que precisam ser definidos antes de executar o mecanismo. Mas a decisão de aumentar o número de parâmetros livres é sempre baseada em uma análise custo/benefício, e acreditamos que os parâmetros que acrescentamos compensam seus custos ao aumentarem grandemente o realismo e generalidade da simulação. Como vimos, com apenas dois parâmetros adicionais ( $\alpha$ e $\gamma$ ) fomos capazes de abarcar uma vasta gama de achados complexos e intrincados que emergem sob esquemas múltiplos. E, com mais um único parâmetro livre $(\lambda)$, pudemos simular comportamento de timing que é coerente sob diferentes níveis de análise.

Com todas as engrenagens colocadas, a $t$ MPR foi capaz de simular, de forma integrada e realista, (a) distribuições de IRT, (b) padrões intra-sessão do responder, (c) a relação entre as taxas de resposta e de reforçamento sob esquemas VI, (d) a relação entre as taxas de resposta e de reforçamento sob esquemas FR, (e) contraste comportamental, (f) os padrões intra-sessão subjacentes ao contraste comportamental, (g) a desaceleração da extinção por reforçamento alternativo, (h) o comportamento de timing que emerge sob condições de reforçamento previsível e (i) a relação entre as taxas de resposta e reforçamento sob esquemas FI. A máquina obteve esses resultados com virtualmente as mesmas configurações ao longo de todos os experimentos. Essas configurações foram baseadas em estimativas de parâmetros frequentemente encontradas na literatura, com algumas delas mensuráveis por métodos independentes.

Além de abarcar um domínio experimental amplo, a máquina ofereceu insights valiosos sobre seus modelos componentes. Como vimos no Capítulo 3, a simulação tornou aparente que as simplificações necessárias para construir as equações de forma fechada da MPR podem fazer com que alguns parâmetros absorvam erros de medida, induzindo estimativas enganosas de valores. Ela também levantou a questão de a qual tipo de aprendizagem estamos nos referindo quando dizemos que um organismo está aprendendo 
timing. Finalmente, ela nos ajudou a compreender como os processos paralelos da MPR (e, depois, da LeT) operam em conjunto, em tempo real, para produzir responder operante.

Mas a utilidade dessa arquitetura comportamental reside não apenas nos resultados apresentados aqui, mas nas possibilidades que ela sugere. A implementação completa de controle de estímulos, esquemas concorrentes, resistência à mudança, omissão de reforçamento e desconto de atraso de reforçamento são apenas alguns dos próximos passos que podem ser dados. Em todos os casos, a abordagem deve ser utilitária: cada parte da arquitetura pode ser substituída por uma alternativa que se prove melhor, como a boa prática da ciência requer.

Ao final, como com qualquer artefato científico, a máquina que apresentamos não deve ser julgada pelas questões que responde, mas pelas questões que levanta - e pelo diálogo que se segue. 


\section{REFERÊNCIAS}

Anderson, J. R. (1996). ACT: A simple theory of complex cognition. American Psychologist, 51, 355-365.

Anderson, J. R., Bothell, D., Byrne, M. D., Douglass, S., Lebiere, C., \& Qin, Y. (2004). An integrated theory of the mind. Psychological Review, 111, 1036-1060.

Avila, I., Reilly, M. P., Sanabria, F., Posadas-Sánchez, D., Chavez, C. L., Banerjee, N., Killeen, P., \& Castañeda, E. (2009). Modeling operant behavior in the Parkinsonian rat. Behavioural Brain Research, 198, 298-305.

Bittar, E. G. (2010). Within-session responding under several variable interval schedules of reinforcement. Unpublished manuscript.

Bittar, E. G., Del-Claro, K., Bittar, L. G., \& Silva, M. C. P. (2012). Towards a mathematical model of within-session operant responding. Journal of Experimental Psychology: Animal Behavior Processes, 38, 292-302.

Bizo, L. A., Kettle, L. C., \& Killeen, P. R. (2001). Rats don't always respond faster for more food: The paradoxical incentive effect. Animal Learning \& Behavior, 29, 66-78.

Bizo, L. A., \& Killeen, P. R. (1997). Models of ratio schedule performance. Journal of Experimental Psychology: Animal Behavior Processes, 23, 351-367.

Bradshaw, C. M., \& Killeen, P. R. (2012). A theory of behaviour on progressive ratio schedules, with applications in behavioural pharmacology. Psychopharmacology, $222,549-564$.

Bradshaw, C. M., Szabadi, E., \& Bevan, P. (1978). Relationship between response rate and reinforcement frequency in variable-interval schedules: the effect of the concentration of sucrose reinforcement. Journal of the Experimental Analysis of Behavior, 29, 447-452.

Catania, A. C., \& Reynolds, G. S. (1968). A quantitative analysis of the responding maintained by interval schedules of reinforcement. Journal of the Experimental Analysis of Behavior, 11, 327-383.

Ettinger, R. H., Reid, A. K., \& Staddon, J. E. R. (1987). Sensitivity to molar feedback functions: A test of molar optimality theory. Journal of Experimental Psychology: Animal Behavior Processes, 13, 366-75.

Ferster, C. B., \& Skinner, B. F. (1957). Schedules of reinforcement. New York: AppletonCentury-Crofts.

Gibbon, J., Church, R. M., \& Meck, W. H. (1984). Scalar timing in memory. In L. Allan \& J. Gibbon (Eds.), Timing and time perception (pp. 52-77). New York: Annals of the New York Academy of Sciences. 
Herrnstein, R. J. (1970). On the law of effect. Journal of the Experimental Analysis of Behavior, 13, 243-266.

Herrnstein, R. J. (1974). Formal properties of the matching law. Journal of the Experimental Analysis of Behavior, 21, 159-164.

Heyman, G. M., \& Monaghan, M. M. (1987) Effects of changes in response requirement and deprivation on the parameters of the matching law equation: New data and review. Journal of Experimental Psychology: Animal Behavior Processes, 13, 384-94.

Killeen, P. R. (1994). Mathematical principles of reinforcement. Behavioral and Brain Sciences, 17, 105-172.

Killeen, P. R. (1995). Economics, ecologics, and mechanics: the dynamics of responding under conditions of varying motivation. Journal of the Experimental Analysis of Behavior, 64, 405-431.

Killeen, P. R. (1998). The first principle of reinforcement. In C. Wynne \& J. E. R. Staddon (Eds.), Models of action (pp. 127-156). Mahwah, NJ: Erlbaum.

Killeen, P. R., \& Fetterman, J. G. (1988). A behavioral theory of timing. Psychological Review, 95, 274-285.

Killeen, P. R., Hall, S. S., Reilly, M. P., \& Kettle, L. C. (2002). Molecular analyses of the principal components of response strength. Journal of the Experimental Analysis of Behavior, 78, 127-160.

Killeen, P. R., Hanson, S. J., \& Osborne, S. R. (1978). Arousal: its genesis and manifestation as response rate. Psychological Review, 85, 571-581.

Killeen, P. R., \& Sitomer, M. T. (2003). MPR. Behavioural Processes, 62, 49-64.

Kleen, J. K., Sitomer, M. T., Killeen, P. R., \& Conrad, C. F. (2006). Chronic stress impairs spatial memory and motivation for reward without disrupting motor ability and motivation to explore. Behavioral Neuroscience, 120, 842-851.

Machado, A. (1997). Learning the temporal dynamics of behavior. Psychological Review, 104, 241-265.

Machado, A., Malheiro, M. T., \& Erlhagen, W. (2009). Learning to time: a perspective. Journal of the Experimental Analysis of Behavior, 92, 423-458.

McSweeney, F. K., Hatfield, J., \& Allen, T. M. (1990). Within-session responding as a function of post-session feedings. Behavioural Processes, 22, 177-186.

McSweeney, F. K., \& Hinson, J. M. (1992). Patterns of responding within sessions. Journal of the Experimental Analysis of Behavior, 58, 19-36. 
McSweeney, F. K., Roll, J. M., \& Weatherly, J. N. (1994). Within-session changes in responding during several simple schedules. Journal of the Experimental Analysis of Behavior, 62, 109-132.

McSweeney, F. K., Swindell, S., Murphy, E. S., \& Kowal, B. P. (2004). The relation of multiple-schedule behavioral contrast to deprivation, time in session, and withinsession changes in responding. Learning \& Behavior, 32, 190-201.

McSweeney, F. K., \& Weatherly, J. N. (1998). Habituation to the reinforcer may contribute to multiple-schedule behavioral contrast. Journal of the Experimental Analysis of Behavior, 69, 199-221.

Newell, A. (1990). Unified theories of cognition. Cambridge, MA: Harvard University Press.

Nevin, J. A., Tota, M. E., Torquato, R. D., \& Shull, R. L. (1990). Alternative reinforcement increases resistance to change: Pavlovian or operant contingencies? Journal of the Experimental Analysis of Behavior, 53, 359-379.

Podlesnik, C. A., \& Shahan, T. A. (2009). Behavioral momentum and relapse of extinguished operant responding. Learning \& Behavior, 37, 357-364.

Poling, A. (2010). Looking to the future: Will behavior analysis survive and prosper? The Behavior Analyst, 34, 37-40.

Reynolds, G. S. (1961a). Behavioral contrast. Journal of the Experimental Analysis of Behavior, 4, 57-71.

Reynolds, G. S. (1961b). An analysis of interactions in a multiple schedule. Journal of the Experimental Analysis of Behavior, 4, 107-117.

Reynolds, G. S. (1968). Induction, contrast, and resistance to extinction. Journal of the Experimental Analysis of Behavior, 11, 453-457.

Sanabria, F., Acosta, J. I., Killeen, P. R., Neisewander, J. L., \& Bizo, L. A. (2008). Modeling the effects of fluoxetine on food-reinforced behavior. Behavioural Pharmacology, $19,61-70$.

Staddon, J. E. R., \& Bueno, J. L. O. (1991). On models, behaviorism and the neural basis of learning. Psychological Science, 2, 3-11.

Staddon, J. E. R., \& Higa, J. (1999). Time and memory: Towards a pacemaker-free theory of interval timing. Journal of the Experimental Analysis of Behavior, 71, 215-251.

Swithers, S. E., \& Hall, W. G. (1994). Does oral experience terminate ingestion? Appetite, 23, 113-138.

Thompson, W. T. (1884). Notes of Lectures on molecular dynamics and the wave theory of light. Lecture XX. Delivered at Johns Hopkins University, Baltimore, MD. 
Williams, B. A. (1983). Another look at contrast in multiple schedules. Journal of the Experimental Analysis of Behavior, 39, 345-384. 


\section{APÊNDICE}

Sob esquemas FR, a última resposta (reforçada) é sempre uma resposta-alvo. De acordo com a Equação 7, essa contingência por si só garante que pelo menos uma fração $\beta$ dos efeitos do reforçador será absorvida pela classe operante. Mas e os efeitos remanescentes? Em qual nível eles também serão absorvidos por essa classe?

Para responder essa questão, primeiramente precisamos estimar o comprimento $L$ da trajetória que precede a resposta reforçada. Isso é simples: como a probabilidade de uma resposta-alvo em cada ponto da trajetória é $C$, o comprimento esperado será dado por

$$
L=\frac{N-1}{C}
$$

onde $N$ é o requisito de razão. Se estamos executando um esquema FR 2 com $C=.25$, por exemplo, antes da segunda resposta-alvo nós esperaremos uma trajetória comportamental com comprimento igual a 4 .

O próximo passo é pesar a contribuição da resposta-alvo em cada ponto dessa trajetória por sua probabilidade $(C)$. A contribuição de uma resposta-alvo que está a $i$ respostas de distância do reforçamento é dada por $\beta(1-\beta)^{i}$. Depois, calculamos o peso das respostas-alvo na memória no momento do reforçamento como a soma das contribuições ponderadas mais o peso $\beta$ da resposta reforçada. De acordo com as Equações 13 e 14 no texto, essa quantidade determinará o próximo valor de $C$, de modo que

$$
C_{n}=\beta+\sum_{i=1}^{L} \beta(1-\beta)^{i} C_{n-1},
$$

que pode ser resolvido como

$$
C_{n}=\beta+C_{n-1}\left[-1+(1-\beta)^{L}\right](\beta-1) .
$$

Como a variável $L$ nas Equações A2 e A3 é determinada por $C_{n-1}$, nós ficamos presos ao tentar resolver essa função recursiva. No entanto, enquanto $n \rightarrow \infty, C_{n}$ tende a um ponto de equilíbrio que pode ser aproximado por

$$
\lim _{n \rightarrow \infty} C_{n}=1-(1-\beta) e^{(1-N) \beta^{1.23}} .
$$


A Equação A4 é o modelo de acoplamento sob esquemas FR que foi usado para ajustar o modelo aos dados do Experimento 2 no texto. 